\title{
Circadian Clock-Controlled Drug Metabolism: Implications for Chronotherapeutics
}

\author{
(1) Danyi Lu, ${ }^{1}$ Mengjing Zhao, ${ }^{1}$ Min Chen, and @Baojian Wu \\ Research Center for Biopharmaceutics and Pharmacokinetics, College of Pharmacy, Jinan University, Guangzhou, \\ China (D.L., M.Z., M.C., B.W.) and International Cooperative Laboratory of Traditional Chinese Medicine Modernization \\ and Innovative Drug Development of Chinese Ministry of Education (MOE), College of Pharmacy, Jinan University, \\ Guangzhou, China (B.W.)
}

Received January 7, 2020; accepted February 18, 2020

\section{ABSTRACT}

Dependence of drug metabolism on dosing time has long been recognized. However, only recently are the underlying mechanisms for circadian drug metabolism being clarified. Diurnal rhythmicity in expression of drug-metabolizing enzymes is believed to be a key factor determining circadian metabolism. Supporting the notion that biological rhythms are generated and maintained by the circadian clock, a number of diurnal enzymes are under the control of the circadian clock. In general, circadian clock genes generate and regulate diurnal rhythmicity in drug-metabolizing enzymes via transcriptional actions on one or two of three cis-elements (i.e., E-box, D-box, and Rev-erb response element or RAR-related orphan receptor response element). Additionally, cycling or clockcontrolled nuclear receptors such as hepatocyte nuclear factor $4 \alpha$ and peroxisome proliferator-activated receptor $\gamma$ are contributors to diurnal enzyme expression. These newly discovered mechanisms for each of the rhythmic enzymes are reviewed in this article. We also discuss how the rhythms of enzymes are translated to circadian pharmacokinetics and drug chronotoxicity, which has direct implications for chronotherapeutics. Our discussion is also extended to two diurnal transporters ( $P$-glycoprotein and multidrug resistance-associated protein 2) that have an important role in drug absorption. Although the experimental evidence is lacking in metabolism-based chronoefficacy, circadian genes (e.g., Reverbo $)$ as drug targets are shown to account for diurnal variability in drug efficacy.

\section{SIGNIFICANCE STATEMENT}

Significant progress has been made in understanding the molecular mechanisms for generation of diurnal rhythmicity in drugmetabolizing enzymes. In this article, we review the newly discovered mechanisms for each of the rhythmic enzymes and discuss how the rhythms of enzymes are translated to circadian pharmacokinetics and drug chronotoxicity, which has direct implications for chronotherapeutics.

\section{Introduction}

It has been long recognized that the effects of many drugs depend on dosing time (time of administration), with a variability of up to 10 -fold

This work was supported by the National Natural Science Foundation of China (Nos. 81722049 and 81803620 ), the Local Innovative and Research Teams Project of Guangdong Pearl River Talents Program (No. 2017BT01Y036), the Natural Science Foundation of Guangdong Province (No. 2018A030310048), and the Guangzhou Science and Technology Project (No. 201904010472).

${ }^{1}$ D.L. and M.Z. contributed equally to this work.

https://doi.org/10.1124/dmd.120.090472.
(Levi and Schibler, 2007; Dallmann et al., 2014). To date, time-varying effects have been documented for over 300 medications (Bruguerolle, 1998; Baraldo, 2008; Innominato et al., 2010; Lévi and Okyar, 2011; Kaur et al., 2013; Ohdo et al., 2019; Ruben et al., 2019). Strikingly, chronotherapy with drugs generates better efficacy (about 2-fold) and tolerability (up to 5-fold) compared with conventional therapy (Koyanagi et al., 2003; Lévi, 2003; Iurisci et al., 2009; Lévi and Okyar, 2011). The mechanisms for time-dependent drug effects appear to be complicated. Of note, circadian pharmacokinetics (also called chronopharmacokinetics) may be one of the main sources of time-varying drug effects (Baraldo, 2008; Ruben et al., 2019).

ABBREVIATIONS: AF, activation function; AhR, aryl hydrocarbon receptor; APAP, acetaminophen; Bcrp, breast cancer resistance protein; Bhmt, betaine homocysteine methyltransferase; Bmal1, brain and muscle Arntl-like protein 1; Car, constitutive androstane receptor; Cbs, cystathionine $\beta$; Cbs, cystathionine $\beta$-synthase; Clock, circadian locomoter output cycles kaput; CPA, cyclophosphamide; Cry, crytochrome; Cth, cystathionine $\gamma$-lyase; Dbp, albumin D site-binding protein; E4bp4, E4-binding protein 4; Fmo, flavin-containing monooxygenase; HIf, hepatic leukemia factor; $\mathrm{Hnf} 4 \alpha$, hepatocyte nuclear factor $4 \alpha$; Lrh-1, liver receptor homolog 1; Lxr, liver X receptor; Mrp, multidrug resistance-associated protein; NF-кB, nuclear factor-кB; NIrp3, NOD-like receptor family pyrin domain containing 3; NR, nuclear receptor; P450, cytochrome P450; PAR bZIP, PARdomain basic leucine zipper; Per, period; P-gp, P-glycoprotein; Ppar, peroxisome proliferator-activated receptor; Pxr, pregnane X receptor; RevRE, Rev-erb response element; Ror, RAR-related orphan receptor; RORE, Ror response element; Rxr, retinoid-X receptor; SCN, suprachiasmatic nucleus; Shp, small heterodimer partner; Sult, sulfotransferase; Tef, thyrotroph embryonic factor; TTFL, transcriptional-translational feedback loop; Ugt, UDP-glucuronosyltransferase; Vdr, vitamin D receptor; ZT, zeitgeber time. 
Dependence of pharmacokinetics on dosing time has been described for over 50 drugs in humans (Dallmann et al., 2014; Ohdo et al., 2019). Unfortunately, the molecular mechanisms underlying these chronopharmacokinetic events remain largely unknown.

Metabolism (biotransformation catalyzed by drug-metabolizing enzymes) is a main defense mechanism of the body against xenobiotic threats and is regarded as a key determinant of pharmacokinetics (and drug exposure) and therefore of pharmacological effects (Wilkinson, 2005; Benedetti et al., 2009). On the other hand, toxic metabolites may be generated from metabolism reactions, causing adverse effects and disfavoring new drug development (Guengerich, 2006). Over 50 years ago, Radzialowski and Bousquet (1968) reported dosing time-dependent drug metabolism in rodents, suggesting a potential role of circadian metabolism in determining chronopharmacokinetics. From then on, great progress has been made in understanding the molecular mechanisms underlying rhythmic expression of drugmetabolizing enzymes. These newly discovered mechanisms for each of the rhythmic enzymes are reviewed in this article. We also discuss how the rhythms of enzymes are translated to circadian pharmacokinetics and drug chronotoxicity, which has direct implications for chronotherapeutics. Our discussion is also extended to two diurnal transporters [P-glycoprotein (P-gp) and Mrp2] that have an important role in drug absorption.

\section{Drug-Eliminating System}

The body possesses a sophisticated system to eliminate drugs. Historically, drug elimination consists of phase I metabolism, phase II metabolism, and phase III excretion (Döring and Petzinger, 2014; Almazroo et al., 2017). Phase I metabolism (modification reactions) includes oxidation, reduction, and hydrolysis, which introduce new functional groups, such as hydroxyl, carboxyl, and amino groups, into the drug structure (Testa et al., 2012). Enzymes involved in phase I reactions include $\mathrm{P} 450$ (cytochrome $\mathrm{P} 450$ ), flavin-containing monooxygenase (FMO), monoamine oxidase, aldehyde oxidase, alcohol dehydrogenase, aldehyde dehydrogenase, and carboxylesterase. In phase II reactions, drugs are conjugated with a hydrophilic group, generating polar metabolites that are more excretable (Testa et al., 2012). Major phase II enzymes are the UDP-glucuronosyltransferases (UGTs), sulfotransferases (SULTs), glutathione S-transferases, and arylamine $\mathrm{N}$-acetyltransferases. P450s are major players in phase I metabolism of drugs/xenobiotics and endogenous compounds, such as steroid hormones (Zanger and Schwab, 2013). UGT-mediated glucuronidation reactions account for a high portion $(\sim 35 \%)$ of phase II drug metabolism (Meech et al., 2019). Overall, P450s and UGTs contribute to $40 \%$ and $14 \%$ of total drug metabolism, respectively (Testa et al., 2012). Of 125 Federal Drug Administration-approved drugs (2006-2015), formation of major metabolites ( $\geq 10 \%$ of drug dose) is primarily catalyzed by P450s (52.5\%), followed by UGTs (11.7\%) (Cerny, 2016).

Efflux transporters or exporters are a class of transporters that mediate the phase III excretion process. P-gp, multidrug resistance-associated proteins (MRPs), and breast cancer resistance protein (BCRP) are the main transporters in efflux transport of drugs and metabolites (Xu et al., 2005; Döring and Petzinger, 2014). Transporter-mediated excretion is necessary for many hydrophilic drug molecules and metabolites (particularly phase II metabolites) because they cannot passively diffuse out of cells (Schinkel and Jonker, 2003; Choi and Yu, 2014). The liver, intestine, and kidney (known as major drug-eliminating organs) express high levels of phase I and II enzymes, as well as efflux transporters (Ohtsuki et al., 2012; Schaefer et al., 2012; Nakamura et al., 2016).

The cross talk between drug metabolism and transport has long been recognized, a phenomenon termed "enzyme-transporter interplay"
(Benet, 2009). The most famous example is the CYP3A-P-gp interplay. Such interplay has implications for better understanding of pharmacokinetics and bioavailability of drugs that are substrates of both CYP3A and P-gp (Christians et al., 2005). Mechanistically, drug substrates have more chance to encounter the enzymes (CYP3A) because of P-gp-mediated excretion and reabsorption, resulting in enhanced drug metabolism and clearance (Mudra et al., 2011). In addition, the interplay between phase II enzymes and efflux transporters has also been well characterized (Jeong et al., 2005; Wu, 2012; Wang et al., 2016). Chemical inhibition or genetic knockdown of Mrps/Bcrp leads to reduced conjugation of drug/xenobiotic, highlighting the dependence of cellular metabolism on efflux transport.

\section{Circadian Clock System}

The rotation of the Earth causes daily changes in the environment, such as temporal variations in sunlight, temperature, and humidity. To adapt to this changing environment, almost all organisms on Earth have evolved a circadian timing system that generates and regulates circadian rhythms in physiological, cellular, and biochemical processes, as well as in behaviors, such as body temperature, cell metabolism, hormone release, and sleep-wake cycle in mammals ((Paschos et al., 2010) Feng and Lazar, 2012; (Thaiss et al., 2015)). The term "circadian" is derived from the Latin word "circa diem" which means "about a day." Preservation of circadian rhythms is essential for human health. Chronic disruption of circadian rhythms is linked to a variety of pathogenic conditions, including metabolic syndromes, inflammatory and cardiovascular diseases, and cancers (Table 1) (Germain and Kupfer, 2008; Gery and Koeffler, 2010; Maury et al., 2010; Portaluppi et al., 2012; Mattis and Sehgal, 2016).

The circadian clock system consists of three main components (Fig. 1): 1) external inputs, such as light, oxygen level, and temperature, that provide time cues (so-called time givers or zeitgebers); 2) the central clock (pacemaker) that senses the input signals; and 3) the output pathways (or effector pathways) through which the central clock generates and maintains biological rhythms (Takahashi, 2017; Gaspar et al., 2019). In mammals, the central clock is located in the suprachiasmatic nucleus ( $\mathrm{SCN}$ ) of the hypothalamus and is also called the master clock. Molecular clocks presented in other tissues/organs are called peripheral or slave clocks (Yoo et al., 2004). The central clock synchronizes peripheral clocks via neural and hormonal pathways, although feedback from the periphery to the SCN is also possible (Mrosovsky, 1996). It is noteworthy that circadian oscillations can be self-sustained (independent of SCN) in peripheral tissues (Yoo et al., 2004).

All molecular clocks consist of over 15 circadian genes that form multiple transcriptional-translational feedback loops (TTFLs) (Fig. 1) (Feng and Lazar, 2012; Takahashi, 2017). In the main TTFL, Bmal1 and Clock form a heterodimer that activates transcription of target genes, including periods (Pers) and crytochromes (Crys), via E-box cis-element (Bass and Takahashi, 2010; Takahashi, 2017). As the protein levels increase, Pers and Crys inhibit the activity of Bmal1/Clock to lower the expression of themselves and others, thereby generating a circadian oscillation in gene expression (Bass and Takahashi, 2010; Takahashi, 2017). A new transcriptional-translational cycle can be initiated when Pers and Crys are reduced to a low level due to protein degradation via phosphorylation and ubiquitination (Bass and Takahashi, 2010; Curtis et al., 2014).

The second TTLF is composed of three transcriptional activators (Ror $\alpha, \beta, \gamma)$ and two repressors (Rev-erb $\alpha / \beta)$ (Fig. 1) (Liu et al., 2008). Rors and Rev-erbs compete for binding to the same cis-element [named Ror response element (RORE) or Rev-erb response element (RevRE)] 
TABLE 1

Pathological conditions associated with chronic circadian disruption

\begin{tabular}{|c|c|c|}
\hline Pathogenic Conditions & Consequences and Potential Mechanisms & References \\
\hline Cancer & $\begin{array}{l}\text { Circadian disruption promotes cancer progression through enhancing the stemness and } \\
\text { tumor-initiating potential of tumor cells and creating an immunosuppressive shift in } \\
\text { the tumor microenvironment. }\end{array}$ & Hadadi et al., 2019 \\
\hline Diabetes & $\begin{array}{l}\text { Circadian disruption accelerates type } 2 \text { diabetes mellitus through inducing pancreatic } \\
\beta \text {-cell loss and dysfunction. }\end{array}$ & Gale et al., 2011 \\
\hline Obesity & $\begin{array}{l}\text { Circadian dysfunction increases the risk of obesity by disrupting leptin signaling in } \\
\text { adipose tissue. }\end{array}$ & Kettner et al., 2015 \\
\hline $\begin{array}{l}\text { Nonalcoholic fatty } \\
\text { liver disease }\end{array}$ & $\begin{array}{l}\text { Circadian disruption increases the risk for nonalcoholic fatty liver disease that is } \\
\text { associated with the perturbation in metabolism. }\end{array}$ & Shetty et al., 2018 \\
\hline Colitis & $\begin{array}{l}\text { Circadian clock disruption exacerbates experimental colitis through regulation of the } \\
\text { Rev-erb } \alpha / \mathrm{NF}-\kappa \mathrm{B} / \mathrm{Nlrp} 3 \text { pathway. }\end{array}$ & Wang et al., 2018 \\
\hline Inflammation & $\begin{array}{l}\text { Chronic circadian disruption aggravates inflammatory responses due to increased } \\
\text { release of proinflammatory cytokines in peritoneal macrophages. }\end{array}$ & $\begin{array}{l}\text { Castanon-Cervantes et al., } \\
2010\end{array}$ \\
\hline Psychiatric disease & $\begin{array}{l}\text { Disruption of circadian rhythms leads to learning, memory, and cognitive defects } \\
\text { through inducing neuron impairments. }\end{array}$ & Karatsoreos, 2014 \\
\hline
\end{tabular}

(Preitner et al., 2002). Rors induce, whereas Rev-erbs inhibit, the transcription of target genes, including Bmall (Preitner et al., 2002). The third TTLF is driven by Dbp and E4bp4. Dbp and E4bp4 compete for binding to the same DNA motif (called "D-box"), which plays an antagonistic role in regulating expression of target genes, including Per2 (Dbp activates, whereas E4bp4 represses, gene transcription) (Mitsui et al., 2001).

\section{Regulation of Drug-Metabolizing Enzymes by Circadian Clock Genes}

In general, circadian gene expression is generated by a transcriptional mechanism in which core clock genes act on three cis-elements (E-box, D-box. and RORE or RevRE) in the target gene promoter (Fig. 2) ((Takahashi, 2017; Zhao et al., 2019a)). These cis-elements generate a difference in the phase (peak timing) of circadian gene expression (Minami et al., 2013). Peak timing of D-box-driven and RORE-driven expression is delayed by $\sim 5$ and $\sim 13$ hours, respectively, as compared with E-box-driven expression (Minami et al., 2013). Of circadian clock proteins, Bmal1 and Clock act on E-box, and Dbp and E4bp4 act on D-box, whereas Rors and Rev-erbs act on RORE. There is accumulating evidence that these clock proteins (alone or in combination) generate and regulate diurnal rhythms of drug-metabolizing enzymes (Fig. 2).

Bmal1 and Clock. Bmal1 and Clock, the positive elements of the main TTFL in circadian clock, are indispensable for generating circadian gene expression (Takahashi, 2017). Bmall and Clock have been implicated in regulation of drug metabolism, contributing to timevarying drug exposure and toxicity. Bmall and Clock activate transcription of Cyp2a4/5 via direct binding to E-box cis-elements in promoters (Zhao et al., 2019b). Accordingly, knockout of Clock or Bmal1 downregulates Cyp2a4/5 expression in mice (Hatanaka et al., 2010; Zhao et al., 2019b). Clock ablation sensitizes mice to the toxicity of coumarin, a drug detoxified by Cyp2a4/5 (Zhao et al., 2019b). Fmo5 is a circadian gene that is under the control of Bmall. Bmal1 regulation of Fmo5 is attained through direct binding to an E-box
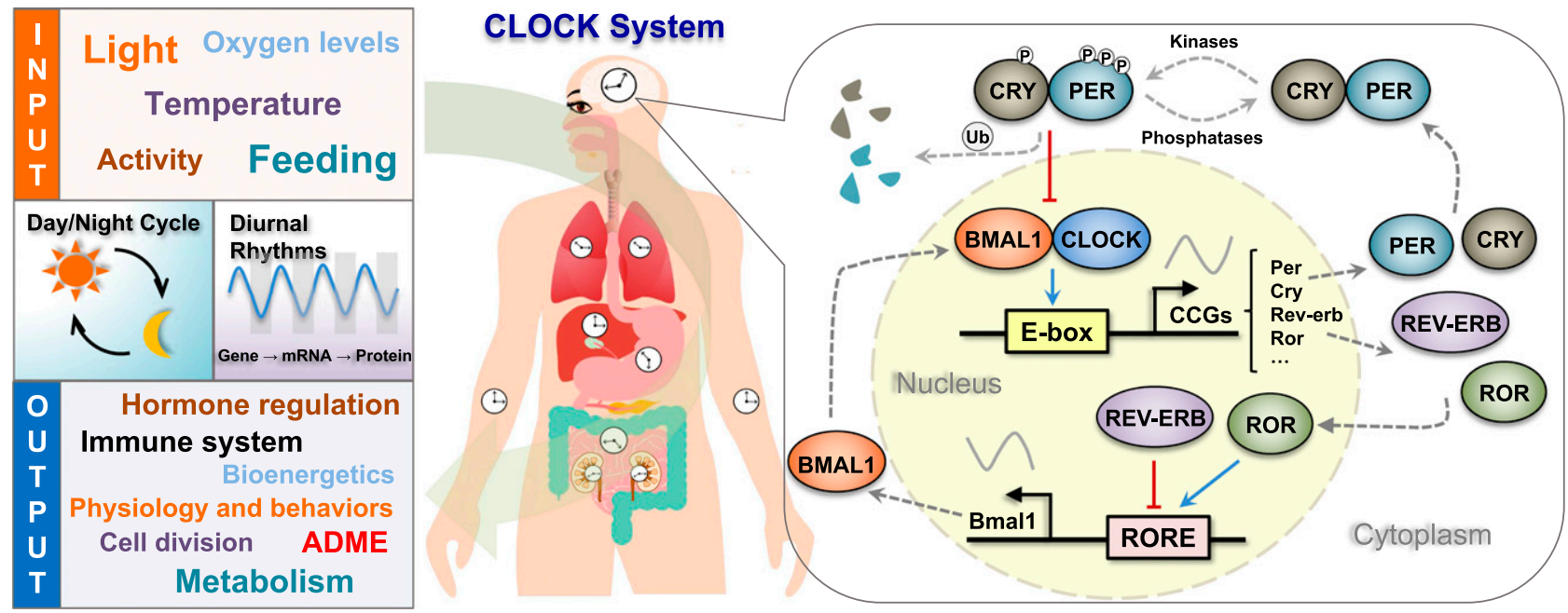

Fig. 1. Circadian clock system in mammals. The mammalian circadian clock system consists of three main components: 1) the external inputs, such as light, oxygen level, and temperature, which provide time cues (so-called time givers or zeitgebers); 2) the central clock (pacemaker), which senses the input signals; and 3) the output pathways (or effector pathways) through which the central clock generates and maintains biological rhythms. At the molecular level, clocks consist of over 15 circadian genes that form multiple TTFLs. In the main TTFL, Bmal1 and Clock form a heterodimer that activates transcription of target genes, including Pers and Crys, via E-box cis-element. As the protein levels increase, Pers and Crys inhibit the activity of Bmal1/Clock to lower the expression of themselves and others, thereby generating a circadian oscillation in gene expression. A new transcriptional-translational cycle can be initiated when Pers and Crys are reduced to low levels due to protein degradation via phosphorylation (P) and ubiquitination (Ub). ADME, absorption, distribution, metabolism and elimination; CCGs, clock-controlled genes. 

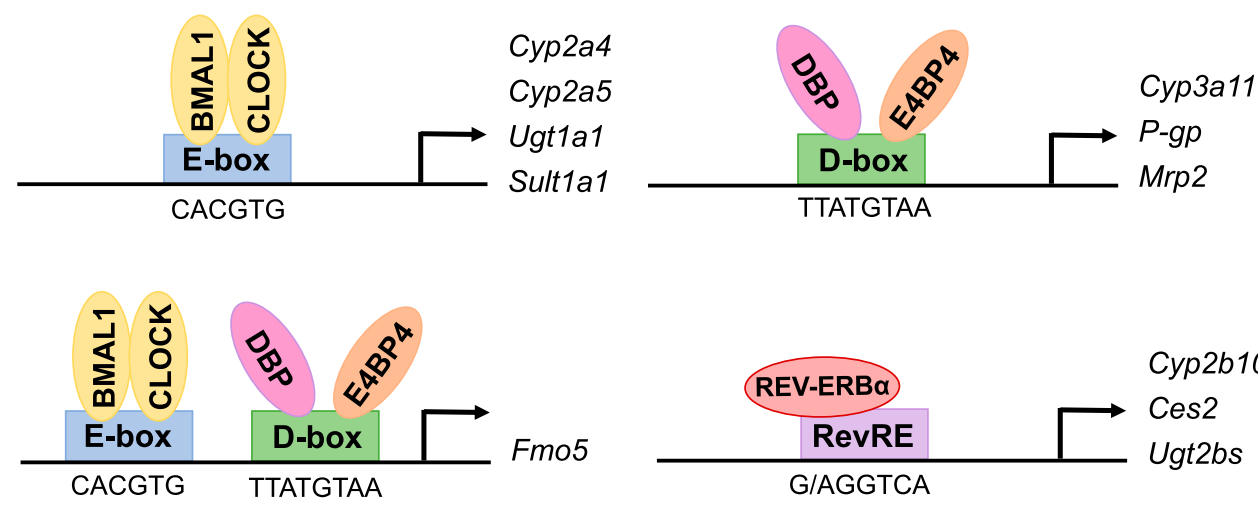

Fig. 2. General modes for generation of diurnal rhythmicity in drug-metabolizing enzymes and transporters through transcriptional actions on E-box, D-box, and/or RevRE cis-elements. Ces, carboxylesterase. and transcriptional activation (Chen et al., 2019a). Bmal1 or Clock ablation leads to downregulation of Fmo5 expression and loss of diurnal rhythm in mouse liver (Chen et al., 2019a). Ugtlal (containing a functional E-box in its promoter) is a direct target of Bmall (Wang et al., 2019). Bmal1 knockout decreases mRNA and protein expression of Ugtla1 and blunts their circadian rhythms in mouse liver (Wang et al., 2019). This is accompanied by a loss of circadian time dependency in bilirubin clearance and a higher sensitivity of mice to chemical-induced hyperbilirubinemia (Wang et al., 2019).

In addition to a direct transcriptional mechanism, Bmal1/Clock may regulate expression of drug-metabolizing enzymes through an indirect mechanism. Bmal1 regulates diurnal expression of Cyp3a11 through Dbp and $\mathrm{Hnf} 4 \alpha$, two direct targets of Bmall and activators of Cyp3a11 (Lin et al., 2019a). Bmal1 deficiency decreases Cyp3a11 expression and abrogates the daily rhythm of Cyp3a11 expression in mouse liver and small intestine (Lin et al., 2019a,b). Also, Bmal1 ablation sensitizes mice to toxicities of Cyp3a11 substrate drugs (such as aconitine, hypaconitine, and triptolide) and blunts the rhythmicity in toxicity due to elevated drug exposure (Lin et al., 2019a,b). Consistently, deletion of Clock or neuronal PAS domain protein 2 (performing similar functions as Clock does in some tissues) in mice reduces Cyp3a11 expression and aggravates the toxicities induced by triptolide and brucine (Zhou et al., 2019b). Clock represses Cyp2b10 transcription through Rev-erb $\alpha / \beta$, two target genes of Clock and repressors of Cyp2b10. Clock ablation upregulates Cyp2b10-mediated metabolism of cyclophosphamide (CPA) (a metabolic pathway generating the toxic metabolite 4hydroxy-CPA), leading to exacerbated CPA toxicity and loss of chronotoxicity (Zhao et al., 2019b). However, the chronotoxicity may not be solely attributed to circadian metabolism and pharmacokinetics because it is also correlated with diurnal sensitivity of target B cells regulated by Bmal1/Clock (Gorbacheva et al., 2005).

Bmall is also involved in the regulation of drug transporters and chronotoxicity. The cardiac glycoside oleandrin displays dosing time-dependent toxicity [ZT2 > ZT10 (ZT, zeitgeber time in a 12-hour light/12-hour dark cycle; ZT0 represents lights on, and ZT12 represents lights off)] in mice that is positively associated with the level of drug exposure (ZT2 > ZT10) (Zhou et al., 2019a). Intestinal ablation of Bmall increases the sensitivity of mice to oleandrin-induced toxicity and abolishes the toxicity rhythmicity (Zhou et al., 2019a). This is because oleandrin is a good substrate transported by P-gp, whose expression and rhythmicity are under the control of Bmal1 (Zhou et al., 2019a). In addition, diurnal expression of intestinal $\mathrm{P}-\mathrm{gp}$ is a contributor to circadian responses of animals to irinotecan (Filipski et al., 2014). Mechanistically, Bmal1 regulates diurnal P-gp expression through activating Hlf (a positive regulator of $\mathrm{P}-\mathrm{gp}$ ) and suppressing E4bp4 (a negative regulator of P-gp) (Zhou et al., 2019a).
Bcrp is rhythmically expressed in mouse liver, kidney, and intestine (Zhang et al., 2009; Hamdan et al., 2012). As a result, the pharmacokinetic behavior of oral sulfasalazine (a Bcrp substrate) is significantly influenced by dosing time (drug exposure: ZT2 > ZT14) (Hamdan et al., 2012). Clock deficiency decreases Bcrp expression and abolishes its rhythm in mouse small intestine (Hamdan et al., 2012). Mechanistic studies reveal that Clock regulates Bcrp through circadian clock-activating transcription factor-4, which periodically binds to Bcrp promoter and activates gene transcription (Hamdan et al., 2012).

Mrp2 expression varies greatly with time of day in both mouse liver and intestine, accounting for diurnal elimination and toxicity of Mrp2 substrates such as bilirubin, phenolsulfonphthalein, methotrexate, and irinotecan (Okyar et al., 2011; Oh et al., 2017; Yu et al., 2019; Wang et al., 2019). Mrp2 mRNA and protein increase in the dark phase and decrease in the light phase in both mouse liver and intestine. Accordingly, hepatobiliary excretion of phenolsulfonphthalein is greater in mice when administered during the dark phase (higher Mrp2 expression) than during the light phase (lower Mrp2 expression) (Oh et al., 2017). Bmal1 has been reported to regulate diurnal expression of Mrp2 in mouse liver and intestine. Loss of Bmal1 decreases Mrp2 expression and blunts the rhythmicity, leading to increased sensitivity of mice to toxicity induced by bilirubin and methotrexate (Wang et al., 2019; Yu et al., 2019). Bmal1 activates Mrp2 transcription via upregulating Dbp (an Mrp2 activator) expression and downregulating E4bp4 (an Mrp2 repressor) expression through Rev-erb $\alpha$ (an E4bp4 repressor) (Fig. 3) (Yu et al., 2019).

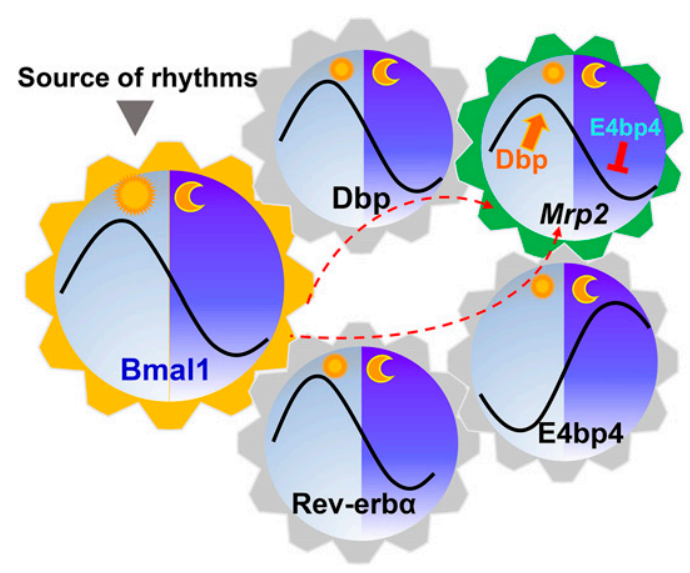

Fig. 3. Bmal1 regulates diurnal expression of Mrp2 through Dbp and Rev-erb $\alpha /$ E4bp4 pathways. To be specific, Bmal1 activates Mrp2 transcription via upregulating Dbp (an Mrp2 activator) expression and downregulating E4bp4 (an Mrp2 repressor) expression through Rev-erb $\alpha$ (an E4bp4 repressor). 
Dbp and E4bp4. Dbp and E4bp4 are two transcriptional factors that compete for binding to the same DNA sequence (called D-box) in the target gene promoter (Mitsui et al., 2001). Dbp activates, whereas E4bp4 inhibits, gene transcription, thereby playing an antagonistic role in regulating gene expression (Mitsui et al., 2001). Reported common target genes of Dbp and E4bp4 are involved in circadian regulation and xenobiotic disposition (Table 2). Dbp and E4bp4 have been identified as important circadian regulators of drug-eliminating genes and chronotoxicity. Dbp and the other two PAR bZIP proteins (Tef and Hlf) may regulate a number of drug-metabolizing enzymes, including Cyp2a, Cyp2c, and Ces3 (Gachon et al., 2006). In particular, the PAR bZIP proteins indirectly regulate diurnal expression of Cyp2b10 through constitutive androstane receptor (Car). Dbp/Tef/Hlf triple knockout mice show an increased susceptibility to toxicity induced by mitoxantrone and CPA, two Cyp2b10 substrates (Gachon et al., 2006). Dbp binds to the promoters of Cyp2a4 and Cyp2a5 and regulates their circadian expression in the mouse liver (Lavery et al., 1999). Consistently, E4bp4 represses Cyp2a 5 transcription by binding to a D-box located at -924/-904 bp, and small heterodimer partner (Shp) promotes Cyp2a5 expression via suppressing E4bp4 activity (Zhang et al., 2018). Moreover, E4bp4 positively regulates Ces2 expression by inhibiting the activity of Rev-erb $\alpha$, a transcriptional repressor of Ces2 (Zhao et al., 2018). Loss of E4bp4 decreases Ces 2 expression and activity in mouse liver, resulting in reduced clearance and improved bioavailability of irinotecan (a Ces2 substrate) (Zhao et al., 2018).

DBP and E4BP4 regulate diurnal expression of human CYP3A4. CYP3A4 mRNA, protein, and enzymatic activity show temporal rhythmicities in serum-shocked HepG2 cells (Takiguchi et al., 2007). DBP binds to a D-box element (located at $-34 /-24$ bp) in CYP3A4 promoter and activates its transcription, whereas E4BP4 antagonizes such effect (Takiguchi et al., 2007). Overexpression of DBP increases CYP3A4 mRNA expression, whereas overexpression of each of the other circadian clock genes (i.e., PER2, $C R Y 1$, and $R E V-E R B \alpha$ ) has no effect (Takiguchi et al., 2007). In addition, Dbp and E4bp4 regulate diurnal Cyp3a11 (the ortholog of human CYP3A4) expression in mouse liver. Dbp binds to a D-box at $-45 /-36$ bp in Cyp3a11 promoter and activates its transcription, whereas E4bp4 binds to a D-box at -1539 / $-1529 \mathrm{bp}$ and represses gene transcription (Lin et al., 2019a; Tong et al., 2019). E4bp4 ablation reduces the systemic exposure of midazolam (a specific Cyp3a11 substrate) in mice through promoting its metabolism by Cyp3a11 (Tong et al., 2019).

Dbp and E4bp4 are also involved in the regulation of diurnal Fmo5 expression and circadian pharmacokinetic of Fmo5 substrates. Fmo5 mRNA, protein and activity display robust rhythmicity in mouse liver, accounting for dosing time-dependent pharmacokinetic profiles of pentoxifylline (an Fmo5 substrate) (Chen et al., 2019a). Deletion of E4bp4 increases hepatic Fmo5 expression and blunts its rhythms in mice (Chen et al., 2019a). In fact, Fmo5 promoter contains two D-boxes (located at -1718 and $-796 \mathrm{bp}$ ). E4bp4 acts on both D-boxes, whereas Dbp acts only on the latter D-box ( -796 bp) (Chen et al., 2019a).

P-gp expression displays a robust fluctuation in multiple tissues, including liver, intestine, and kidney (Ando et al., 2005). E4bp4 and PAR bZIP factors (i.e., Dbp, Tef, and Hlf) participate in circadian regulation of P-gp expression. E4bp4 represses, whereas Hlf activates, $m d r l a$ transcription via competitive binding to a D-box element (please note that mouse P-gp is encoded by $m d r l a, m d r l b$, and $m d r 2$ genes) (Zhou et al., 2019a). Mdr2 promoter also contains a functional D-box through which PAR bZIP factors activate and E4bp4 inhibits gene transcription (Kotaka et al., 2008). Diurnal expression of intestinal P-gp has been shown to be a critical factor influencing daily exposure and toxicity of P-gp substrates such as oleandrin and digoxin (Ando et al., 2005; Zhou et al., 2019a). Quinidine (a P-gp substrate) exposure in brain tissue varies according to the time of administration (Kervezee et al., 2014). This time difference is lost upon P-gp inhibition (Kervezee et al., 2014). In addition, Dbp and E4bp4 play a mediating role in Bmal1 regulation of Mrp2 rhythm (Fig. 3). Dbp and E4bp4 are the target genes of Bmal1 and regulators of Mrp2 (Yu et al., 2019). They bind to the same D-box (-100/-89 bp) element in Mrp2 promoter in a time-dependent manner. The former activates, whereas the latter represses, Mrp2 transcription (Yu et al., 2019).

Rev-erbs and Rors. Rev-erbs $(\operatorname{Rev}-\mathrm{erb} \alpha, \beta)$ and Rors $(\operatorname{Ror} \alpha, \beta, \gamma)$ are transcriptional factors that compete for binding to a specific DNA sequence [named RevRE or RORE, generally composed of an NR half site (AGGTCA) and a preceding 5-bp A/T-rich sequence], thereby regulating gene transcription and expression (Harding and Lazar, 1993, 1995). Although binding to the same sequence, Rev-erbs and Rors generate opposite effects. The former inhibits, whereas the latter activates, target gene transcription. Transcriptional repressor activities of Rev-erbs are associated with enhanced recruitment of nuclear receptor corepressors 1 and histone deacetylase 3 complex to target gene promoter (Zamir et al., 1996; Yin and Lazar, 2005). It is noted that Rev-erbs and Rors are expressed in a tissue-dependent manner (Yang et al., 2006). The ratios between Rev-erbs and Rors are a key determinant to circadian gene expression, providing a mechanism to fine-tune the circadian network and metabolism (Yang et al., 2006).

Rev-erbs and Rors have been identified as regulators of drugmetabolizing genes, impacting circadian metabolism and chronopharmacokinetics. The mRNA expression levels of six Ugt $2 b$ genes (i.e., Ugt2b1, Ugt2b5, Ugt2b35, Ugt2b36, Ugt2b37, and Ugt2b38) show circadian fluctuations in mouse liver (Zhang et al., 2019b).

TABLE 2

Common Dbp/E4bp4 targets and their functions ${ }^{a}$

\begin{tabular}{|c|c|c|}
\hline Targets & Functions & References \\
\hline Perl & A circadian factor that forms a heterodimer with Crys to repress Clock/Bmal1 activity & Mitsui et al., 2001 \\
\hline Arnt & $\begin{array}{l}\text { A cofactor for AhR and HIF-1 that regulates the expression of genes involved in xenobiotic } \\
\text { metabolism }\end{array}$ & Nakabayashi et al., 2013 \\
\hline Cyp $2 a 5$ & A drug-metabolizing enzyme involved in the metabolism and detoxification of xenobiotics & $\begin{array}{l}\text { Lavery et al., 1999; Zhang } \\
\text { et al., } 2018\end{array}$ \\
\hline CYP3A4 & A drug-metabolizing enzyme involved in the metabolism and detoxification of xenobiotics & Takiguchi et al., 2007 \\
\hline Cyp3a11 & A drug-metabolizing enzyme involved in the metabolism and detoxification of xenobiotics & $\begin{array}{l}\text { Lin et al., 2019a; Tong et al., } \\
2019\end{array}$ \\
\hline Cyp7al & The rate-limiting enzyme that catalyzes the conversion of cholesterol to bile acids in the liver & Noshiro et al., 2007 \\
\hline Fmo5 & $\begin{array}{l}\text { A NADPH-dependent flavoenzyme that catalyzes the oxidation of soft nucleophilic heteroatom } \\
\text { centers in drugs, pesticides, and xenobiotics }\end{array}$ & Chen et al., 2019a \\
\hline Mrp2 & An $\mathrm{ABC}$ transporter that mediates the efflux of endogenous/exogenous compounds & Yu et al., 2019 \\
\hline
\end{tabular}

${ }^{a}$ Arnt, aryl hydrocarbon receptor nuclear translocator; HIF-1, hypoxia-inducible factor-1; ABC, ATP-binding cassette. 
Likewise, total Ugt2b protein and activity toward morphine exhibit a circadian rhythm in the liver (Zhang et al., 2019b). Loss of Rev-erb $\alpha$ increases hepatic Ugt2b expression and blunts its rhythm in mice (Zhang et al., 2019b). Mechanistically, Rev-erb $\alpha$ trans-represseses Ugt2b genes via direct binding to a RevRE element, generating a diurnal rhythmicity in Ugt2b expression (Zhang et al., 2019b). Interestingly, Shp blocks the suppressive effects of Rev-erb $\alpha$ on Ugt $2 b$ and modulates morphine metabolism and morphine withdrawal syndrome (Chen et al., 2019b). In addition, Rev-erb $\alpha$ contributes to diurnal expression of Cyp2b10, Cyp4a10, and Cyp4a11 through transcriptional actions on RevRE elements (Zhang et al., 2018). Shp prevents the recruitment of corepressors nuclear receptor corepressors 1/histone deacetylase 3 to Rev-erb $\alpha$, leading to derepression of these P450 genes (Zhang et al., 2018). Rev-erb $\alpha$ is also a transcriptional repressor of Ces2. Overexpression of Rev-erb $\alpha$ represses Ces 2 expression, whereas knockdown of Rev-erb $\alpha$ increases Ces2 expression (Zhao et al., 2018). By acting on the target gene $E 4 b p 4$, Rev-erb $\alpha$ participates in circadian regulation of the metabolic enzymes, such as Fmo5 and Cyp7a1 (Duez et al., 2008; Chen et al., 2019a).

$\mathrm{ROR} \alpha$ and $\mathrm{ROR} \gamma$ regulate expression of human CYP2C8 because knockdown of ROR $\alpha$ or ROR $\gamma$ decreases the mRNA level of CYP2C8 in HepG2 cells (Chen et al., 2009). A RORE element located at -2045 bp in CYP2C8 promoter is identified to be essential for RORmediated trans-activation (Chen et al., 2009). Also, ROR $\alpha$ and ROR $\gamma$ regulate SULT2A1 expression through direct binding to a RORE element in the proximal gene promoter (Ou et al., 2013). Supporting this, SULT2A1 expression is positively correlated with $\mathrm{ROR} \alpha / \gamma$ expression in primary human hepatocytes and in human livers $(\mathrm{Ou}$ et al., 2013). Additionally, overexpression of Ror $\alpha$ stimulates Cyp3a11 expression, although the underlying mechanism remains unknown (Wada et al., 2008).

\section{Circadian Regulation of Drug-Metabolizing Enzymes by Nuclear Receptors}

Nuclear receptors (NRs) are a class of transcription factors, and most of them are ligand-responsive (can be activated by a variety of endogenous and exogenous chemicals) (Mangelsdorf et al., 1995; Belandia and Parker, 2003). In general, an NR protein possesses four modular domains (Fig. 4A): a highly variable N-terminal region, which may harbor an activation function (AF-1); a DNA binding domain containing two zinc-finger motifs; a flexible hinge domain; and a ligand binding domain that harbors an activation function (AF-2). Some NRs, such as CAR and pregnane $\mathrm{X}$ receptor (PXR), work by forming a heterodimer with retinoid-X receptor (Evans and Mangelsdorf, 2014). The heterodimers bind to specific DNA motifs (repeats of nucleotide hexamer AGG/TTCA with variable spacing) and regulate gene transcription (Fig. 4B).

Expression levels of drug-metabolizing enzymes and transporters are under the control of many NRs (Tolson and Wang, 2010; Chen et al., 2012; Li et al., 2019), including CAR, PXR, retinoid-X receptor, peroxisome proliferator-activated receptors (PPARs), farnesoid $\mathrm{X}$ receptor, liver $\mathrm{X}$ receptors (LXRs), vitamin $\mathrm{D}$ receptor (VDR), hepatocyte nuclear factor $4 \alpha(\mathrm{HNF} 4 \alpha)$, liver receptor homolog 1 (LRH-1), and SHP (Fig. 4C). At the same time, these NRs may be circadian clock-controlled proteins (called "cycling NRs"), whose expression levels oscillate with the time of day (Yang et al., 2006). The rhythms of cycling NRs can be propagated to the downstream target genes. The rhythmicity generated via clock output genes is essentially an indirect mechanism as compared with direct regulation by circadian clock genes.

Cycling NRs. Of drug metabolism-related NRs, Pxr, Hnf $4 \alpha$, Shp, Ppar $\alpha$, and Ppar $\gamma$ mRNAs display strong diurnal oscillations (peak-tovalley ratio > 2) in mouse liver (Yang et al., 2006; Oiwa et al., 2007; Zhang et al., 2009). These mRNAs generally peak in the late light phase. Hnf4 $\alpha$ and Ppar $\gamma$ proteins oscillate with time of day (Deng et al., 2018; Lin et al., 2019a). The phase of diurnal Ppar $\gamma$ is shifted about 4 hours because of a potential delay in the translation of mRNA to protein product (Fig. 5) (Deng et al., 2018). Large phase shifts (about 8-12 hours) between protein and mRNA are also observed for Cyp2e1 and Cyp3a11, as well as Bmal1 and Clock (Fig. 5) (Zhang et al., 2018; Lin et al., 2019a). By contrast, there is no mRNA-protein phase shift for clock genes such as Rev-erb $\alpha$, Dbp, E4bp4, and Per2 (Fig. 5) (Narumi et al., 2016). Fxr, Vdr, Lxr, Lrh-1, and AhR show mild or weak fluctuations in mRNA expression (Zhang et al., 2009; Tanimura et al., 2011; Lin et al., 2019a). There are conflicting data regarding diurnal expression of Car in the liver. Lin and coworkers report no circadian time-dependent variations in Car mRNA, consistent with a prior study, although intestinal Car may be diurnally rhythmic (Kawase et al., 2013; Lin et al., 2019a). However, Gachon et al. (2006) show that rhythmic Car in the liver mediates regulation of Cyp2b10 by three PAR bZIP factors.

Unfortunately, the mechanisms for circadian expression of most cycling NRs are poorly understood. However, studies have been
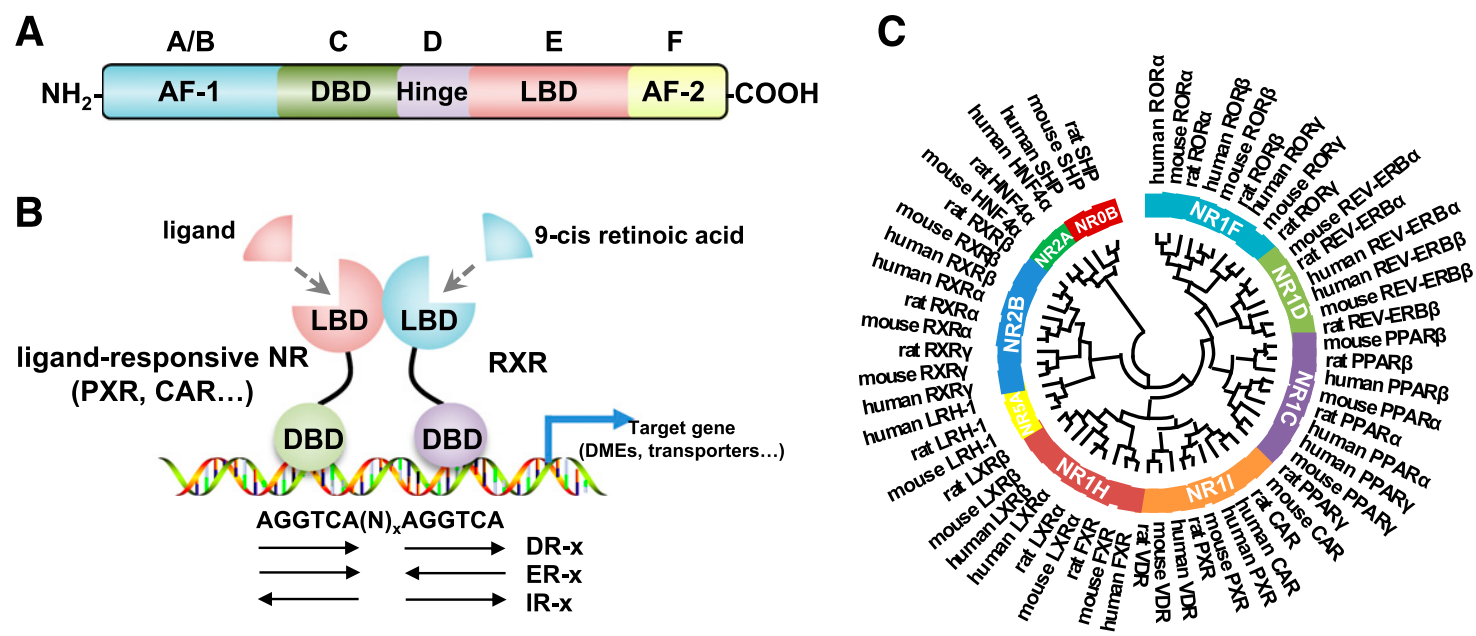

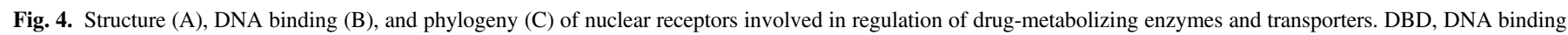

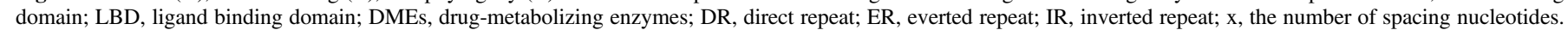



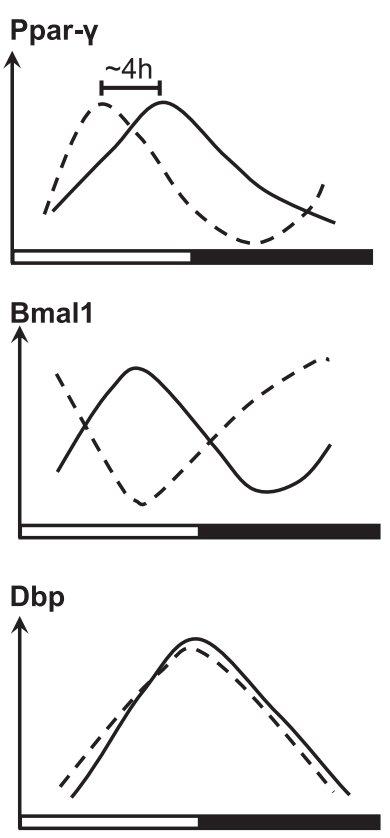

\section{Cyp2e1/3a11}
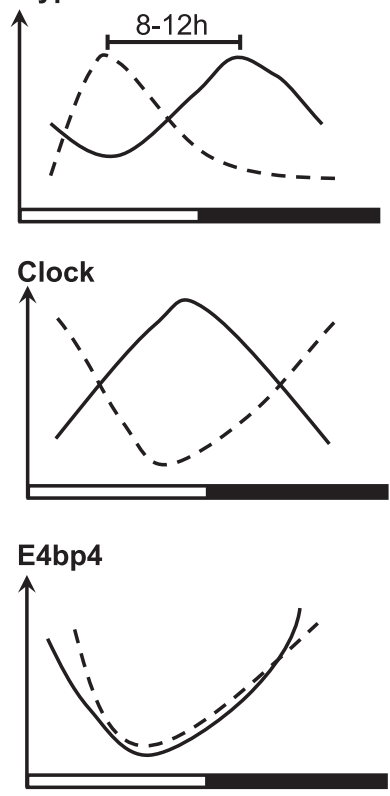
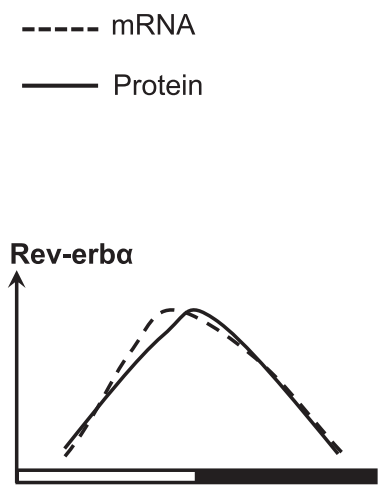

Fig. 5. Diurnal expression patterns of mRNA and protein for clock genes (Bmal1, Clock, $\operatorname{Rev-erb} \alpha$, Dbp, E4bp4, and Per2), nuclear receptor (Ppar $\gamma$ ), and drug-metabolizing enzymes (Cyp2e1/3a11).

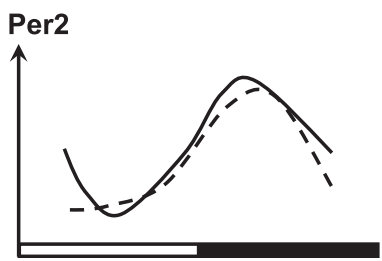

performed to explore how $\mathrm{Hnf} 4 \alpha$ and Shp rhythms are generated. Bmal1 is a source of $\mathrm{Hnf} 4 \alpha$ rhythm, as loss of Bmal1 reduces Hnf $4 \alpha$ expression and abrogates its rhythm in mouse liver (Lin et al., 2019a). Bmal1 regulation of $\mathrm{Hnf} 4 \alpha$ is attained through two E-boxes in the distal region (from -6.1 to $-6.0 \mathrm{~kb}$ ) of P1 promoter (Lin et al., 2019a). Bmal1, Clock, neuronal PAS domain protein 2, and Rev-erb $\alpha$ are potential contributors to circadian expression of Shp. They regulate Shp transcription via binding to the E-box or RevRE element (Oiwa et al., 2007; Duez et al., 2008; Pan et al., 2010).

Cycling NR-Regulated Enzymes. Car is perhaps the first reported cycling NR that regulates circadian expression of a metabolic enzyme (Cyp2b10). Rhythmic Car drives transcription of Cyp2b10 via the phenobarbital-response element, thereby generating a diurnal rhythmicity in Cyp2b10 expression (Gachon et al., 2006; Ripperger and Schibler, 2006). Hnf $4 \alpha$ is another cycling NR that contributes to enzyme rhythmicity. Cyp3a11 rhythm has been shown to be partly associated with direct regulation of $\mathrm{Hnf} 4 \alpha$ via a direct repeat motif spaced by one nucleotide (Lin et al., 2019a). Diurnal Ppar $\gamma$ protein level is significantly correlated with circadian Cyp2a5 mRNA level (Deng et al., 2018). The latter presents a PPAR response element element in gene promoter through which the former activates gene transcription (Deng et al., 2018). These data support a contribution of Ppar $\gamma$ to generation of Cyp2a5 rhythm.

Shp has been implicated in circadian regulation of P450 enzymes (including Cyp1a2, Cyp2a5, Cyp2b10, Cyp2c38, Cyp2c39, Сyp2e1, Cyp3a11, Cyp4a10, and Cyp4a14) via cross talk with multiple circadian proteins (differentiated embryonic chondrocyte-expressed gene 2, E4bp4, Rev-erb $\alpha$, and Lrh-1/Hnf4 $\alpha$ ) (Zhang et al., 2018). Of note, Shp ablation blunts the circadian rhythmicity in acetaminophen-induced hepatotoxicity in mice and alleviates the toxicity by downregulating Cyp2e1-mediated metabolism and reducing formation of the toxic metabolite (Zhang et al., 2018). Rhythmic AhR partially accounts for diurnal expression of Cyp1a1 and Cyp1b1 (Huang et al., 2002). AhRmediated induction of Cypla1 depends on the time of dioxin (an AhR agonist) administration, with the highest extent of induction occurring at night (Huang et al., 2002). Additionally, we recently found that the NR corepressor receptor-interacting protein 140 is rhythmically expressed in the liver, and loss of receptor-interacting protein 140 dampens the rhythm of Cyp2b10 (unpublished data). This may highlight a complexity in the mechanisms for generation of circadian gene expression.

\section{Rhythmic Patterns for Drug-Metabolizing Enzymes}

Current literature reveals two modes (i.e., a general mode and an alternative mode) for generation of diurnal rhythmicity in drugmetabolizing enzymes. In the general mode, circadian clock genes generate and maintain diurnal gene expression via transcriptional actions on one or two of three cis-elements (i.e., E-box, D-box, and RevRE or RORE) (Fig. 2). The alternative mode involves cycling NRs, such as Hnf $4 \alpha$ and Ppar $\gamma$. The rhythms of cycling NRs are propagated to the downstream target genes, many of which are drug-processing genes. The general mode tends to produce two types of diurnal patterns for mRNA expression-namely, a convex pattern (Fig. 6A) and a concave pattern (Fig. 6B). The convex pattern (e.g., Cyp2e1 and Cyp3a11 mRNAs) is characterized by higher expression in the daytime and lower expression at night, with a peak value in the late light phase (Fig. 6A). The concave pattern (e.g., Cyp2b10 mRNA) is characterized by higher expression at night and lower expression in the daytime, with a trough value in the late light phase (Fig. 6B). The mRNA patterns (e.g., Cyp2a5 mRNA) that deviate from the above two typical curves may result from rhythmic modifications of cycling NRs for which translation from mRNA to protein is significantly delayed (e.g., Ppar $\gamma$ ).

\section{Metabolism-Based Chronotoxicity}

Cyp3a11-Mediated Chronotoxicity. Mouse Cyp3a11 (CYP3A4 in humans) is one of the most important enzymes responsible for drug metabolism and detoxification. The role of Cyp3a11 in determining drug chronotoxicity has been well established. Cyp3a11 protein varies according to the time of day, with higher expression at night and lower expression during the daytime (Lin et al., 2019a). As a result, drugs (e.g., aconitine, triptolide, and brucine) detoxified by Cyp3a11 are more toxic to mice in the daytime than at night (Lin et al., 2019a,b; Zhou et al., 2019b). In addition, diurnal expression of Cyp3a11 accounts for chronotoxicity of herbal medicines such as Fuzi (lateral root of Aconitum carmichaeli) and Tripterygium wilfordii (Fig. 7A) (Yang et al., 2020). 
A

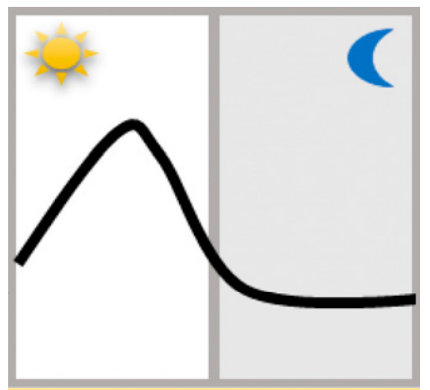

e.g., Cyp2e1 and Cyp3a11 mRNAs
B

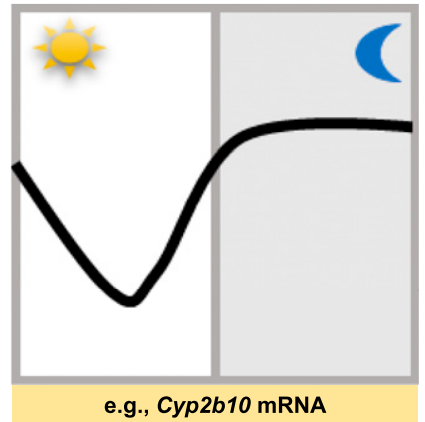

Fig. 6. Representative diurnal convex pattern (A) and concave pattern (B) for rhythmic drug-metabolizing enzymes. The convex pattern (e.g., Cyp2el and Cyp3a11 mRNAs) is characterized by higher expression in the daytime and lower expression at night, with a peak value in the late light phase. The concave pattern (e.g., Cyp 2 b10 mRNA) is characterized by higher expression at night and lower expression in the daytime, with a trough value in the late light phase.

Mice are more sensitive to Fuzi or T. wilfordii (oral gavage) in the light phase than in the dark phase because the toxic ingredients are detoxified by Cyp3a11 (Fig. 7A) (Yang et al., 2020).

Cyp2e1-Mediated Chronotoxicity. Mouse Cyp2e1 protein shows a diurnal pattern in the liver similar to that of Cyp3a11 (higher levels at night and lower levels in the daytime) (Zhang et al., 2018). Acetaminophen (APAP) toxicity exhibits circadian rhythmicity in wild-type mice. APAP injected at ZT14 (dark phase) induces a higher level of toxicity compared with ZT2 (light phase) (Zhang et al., 2018). The chronotoxicity of APAP is attributed to circadian Cyp2e1, which generates the toxic metabolite $N$-acetyl-p-benzoquinone imine from APAP (Zhang et al., 2018). More severe toxicity is thus associated with a higher expression of Cyp2e1.

Chronotoxicity Mediated by Other Cytochrome P450 Enzymes. Coumarin hepatotoxicity displays a diurnal rhythmicity in mice (the toxicity is more severe at ZT2/22 than at ZT14) (Zhao et al., 2019b). The diurnal pattern of toxicity is antiphase to that of Cyp2a4/5, two enzymes primarily responsible for detoxification of coumarin (Zhao et al., 2019b). CPA is a prodrug and is bioactivated by Cyp2b10 to 4-hydroxy-CPA (the active and toxic form) in mice. The severity of CPA toxicity in mice is dosing time-dependent, with higher levels at ZT2/22 and lower levels at ZT10/14 (Zhao et al., 2019b). This results from a diurnal rhythmicity in hepatic Cyp2b10 protein (higher levels at ZT2/22 and lower levels at ZT10/14).

Transporter-Based Chronotoxicity. Zhou et al. (2019a) have reported circadian time-dependent responses of mice to the cardiac glycoside oleandrin, a P-gp substrate. Mice treated during transition times from dark to light (ZT22 to ZT2) are more sensitive to the drug than the mice treated in the late light phase (ZT10) (Zhou et al., 2019a). This time-dependent sensitivity is correlated with the daily variations in drug exposure caused by diurnal expression of intestinal P-gp. Methotrexate is an inhibitor of dihydrofolate reductase and is used to treat neophastic cancers and autoimmune diseases. Oral methotrexate is more toxic in the early dark period (ZT14) than in the early morning period (ZT2) in mice (Yu et al., 2019). This chronotoxicity is mainly dependent on the circadian rhythm of Mrp2 expression. A lower level of toxicity at ZT2 is associated with a higher Mrp2 expression (and a lower drug absorption), and a higher level of toxicity at ZT14 is associated with a lower Mrp2 expression (Yu et al., 2019). We also observe a diurnal rhythmicity in the toxicity of Semen Strychni, which is mainly accounted for by circadian intestinal efflux transport, although circadian hepatic metabolism may also play a role (Fig. 7B).

Chronoefficacy. Theoretically, circadian metabolism would result in time-varying drug efficacy (chronoefficacy) in addition to chronotoxicity due to diurnal variations in drug exposure. However, the experimental evidence is still lacking in metabolism-based
A

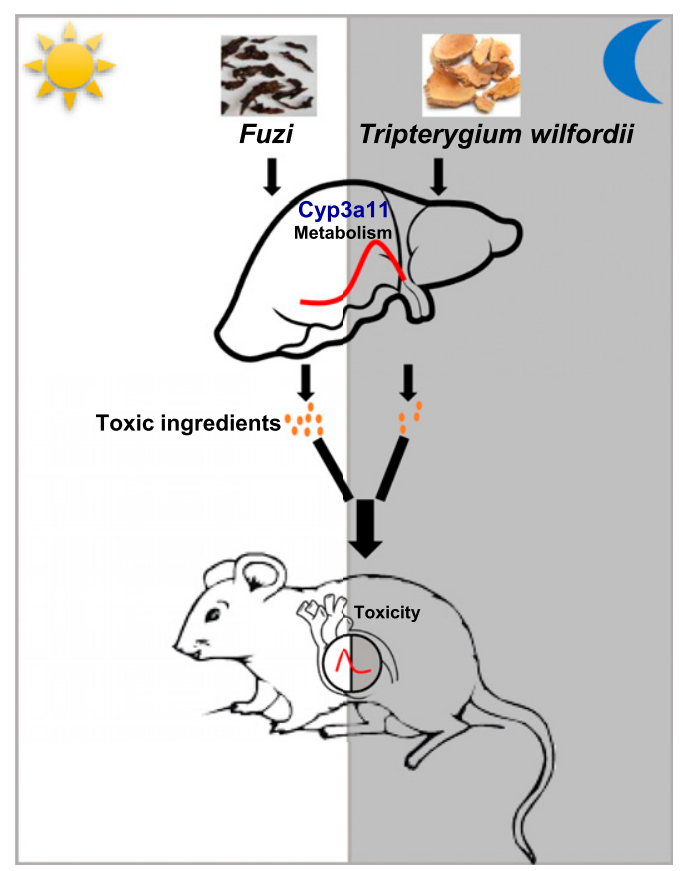

B

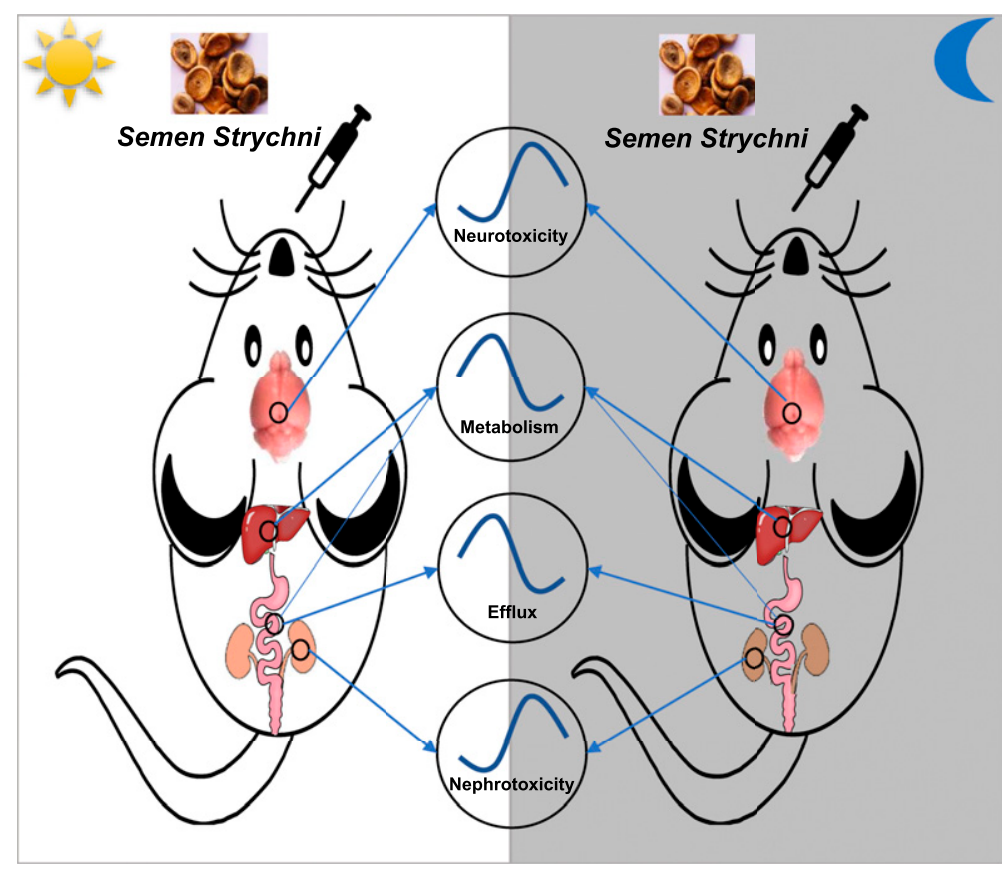

Fig. 7. Metabolism-based chronotoxicity of herbal medicines. (A) Diurnal expression of hepatic Cyp3a11 determines the chronotoxicity of fuzi and T. wilfordii in mice. Mice are more sensitive to fuzi or T. wilfordii (oral gavage) in the light phase than in the dark phase because the toxic ingredients are detoxified by Cyp3a11. (B) Diurnal metabolism and efflux determine the chronotoxicity of Semen Strychni. Mice are more sensitive to Semen Strychni (oral gavage) in the dark phase than in the light phase because the toxic ingredients are detoxified by efflux transporter and drug-metabolizing enzymes. 
TABLE 3

Examples of drugs with chronoefficacy and corresponding clock-controlled drug targets or transporters

\begin{tabular}{|c|c|c|c|c|}
\hline Drug Name & Associated Circadian Protein & Models & Chronoefficacy & References \\
\hline Sulfasalazine & Slc7a11 & Mice with colon 26 xenograft & $\mathrm{ZT} 10>\mathrm{ZT} 22$ & Okazaki et al., 2017. \\
\hline $\mathrm{N}, \mathrm{N}$-diethylaminobenzaldehyde & Aldh3a1 & Mice with $4 \mathrm{~T} 1$ xenograft & $\mathrm{ZT} 14>\mathrm{ZT} 2$ & Matsunaga et al., 2018 \\
\hline Erlotinib & EGFR & Mice with $\mathrm{HCC} 827$ xenograft & $\mathrm{ZT} 8>\mathrm{ZT} 20$ & Lin et al., 2015 \\
\hline Nutlin 3 & p53 & Tumor cells from UV.BAL-5.4G xenograft & $\mathrm{ZT} 14>\mathrm{ZT} 2$ & Horiguchi et al., 2013 \\
\hline Pregabalin & Octn1 & Diabetic mice & $\mathrm{ZT} 14>\mathrm{ZT} 2$ & Akamine et al., 2015 \\
\hline Gabapentin & Calcium channel $\alpha 2 \delta$-1 subunit & Mice with partial sciatic nerve ligation & $\mathrm{ZT} 22>\mathrm{ZT} 10$ & Kusunose et al., 2010 \\
\hline Puerarin & $\operatorname{Rev-erb} \alpha$ & Mice with hyperhomocysteinemia & $\mathrm{ZT} 10>\mathrm{ZT} 22$ & Chen et al., 2020 \\
\hline Berberine & $\operatorname{Rev}-\operatorname{erb} \alpha$ & Mice with chronic colitis & $\mathrm{ZT} 10>\mathrm{ZT} 2$ & Zhou et al., 2020 \\
\hline
\end{tabular}

Slc7a11, solute carrier family 7 member 11; Aldh3a1, aldehyde dehydrogenase family 3 member a1; EGFR, epidermal growth factor receptor; PDGFR, platelet-derived growth factor receptor; p53, 53-kDa protein; Octn1, organic cation/carnitine transporter 1; CCL2, CC chemokine ligand 2.

chronoefficacy. Contrasting with this, there is accumulating evidence that diurnal rhythms of disease severity and drug target can be linked to chronoefficacy (Bass and Lazar, 2016; Ruben et al., 2019). Studies with animals have revealed that drug efficacy could be improved by altering the dosing time according to the expression of clock-controlled drug targets or transporters (Table 3). Rhythmicity in disease severity may involve a circadian disease regulator (e.g., clock genes). The clock gene Rev-erb $\alpha$ has been implicated in regulation of colitis via NF- $\kappa \mathrm{B} / \mathrm{Nlrp} 3$ axis, generating a diurnal rhythmicity in the severity of inflammation (Fig. 8A) (Wang et al., 2018). Zhou et al. (2020) uncover a time-varying berberine (a Rev-erb $\alpha$ agonist) effect on chronic colitis in mice (Fig. 9A). ZT10 dosing generates higher therapeutic efficacy (reflected by lower levels of inflammatory markers) compared with ZT2 dosing (Fig. 9A, Zhou et al., 2020). The time-varying berberine effects are accounted for by diurnal rhythmicities in both colitis severity and drug target (Rev-erb $\alpha$ ) (Zhou et al., 2020). A superior efficacy at ZT10 is associated with less-severe colitis and a higher Rev-erb $\alpha$ expression
(Zhou et al., 2020). The authors propose a dual role for Rev-erb $\alpha$ in the regulation of time-varying berberine effect-namely, generating diurnal rhythmicity in colitis and acting as a rhythmic drug target (Zhou et al., 2020).

Rev-erb $\alpha$ also has been implicated in regulation of homocysteine homeostasis via three catabolic enzymes (Bhmt, Cbs, and $\mathrm{Cth}$ ), generating a diurnal rhythmicity in body homocysteine (Fig. 8B) (Zhang et al., 2019a). Most recently, Chen et al. (2020) reveal the time-varying effects of the Rev-erb $\alpha$ antagonist puerarin on hyperhomocysteinemia in mice (i.e., puerarin treated at ZT10 shows a stronger effect than puerarin treated at ZT22) (Fig. 9B). The circadian effects of puerarin on hyperhomocysteinemia are accounted for by rhythmic Rev-erb $\alpha$, which is identified as the drug target of puerarin (Chen et al., 2020). The cholesterol-lowing effects of short-acting statins (e.g., fluvastatin, simvastatin, lovastatin, and pravastatin) in humans depend on the time of administration (evening $>$ morning) (Awad and Banach, 2018). This is probably because the drug target 3-hydroxy-3-methyl glutaryl CoA

B
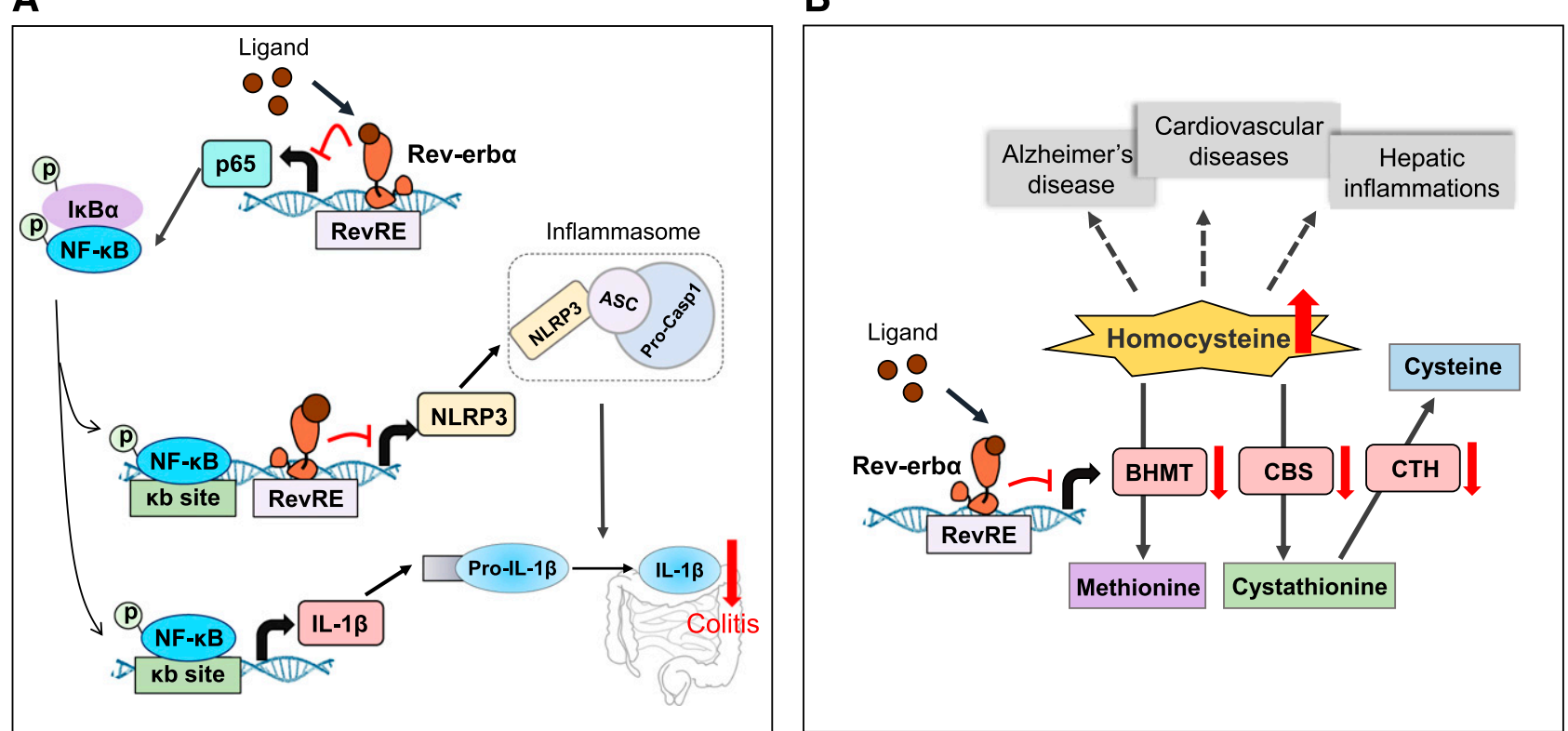

Fig. 8. Rev-erb $\alpha$-based rhythmic diseases. (A) Rev-erb $\alpha$ regulates colitis via the NF- $\kappa \mathrm{B} / \mathrm{Nlrp} 3$ axis. The clock gene Rev-erb $\alpha$ has been implicated in regulation of colitis via the NF- $\kappa$ B/Nlrp3 axis, generating a diurnal rhythmicity in the severity of inflammations (Wang et al., 2018). (B) Rev-erb $\alpha$ regulates homocysteine homeostasis via three catabolic enzymes (Bhmt, Cbs, and Cth). Rev-erb $\alpha$ directly binds to RevRE elements located in the promoters of Bhmt, Cbs, and Cth and downregulates their transcription, leading to elevated homocysteine level and decreased ammonia clearance (Zhang et al., 2019a). IкB $\alpha$, I kappa B alpha; ASC, apoptosis-associated speck-like protein containing a CARD; IL-1 $\beta$, interleukin-1 $\beta$; casp1, caspase-1. 
A

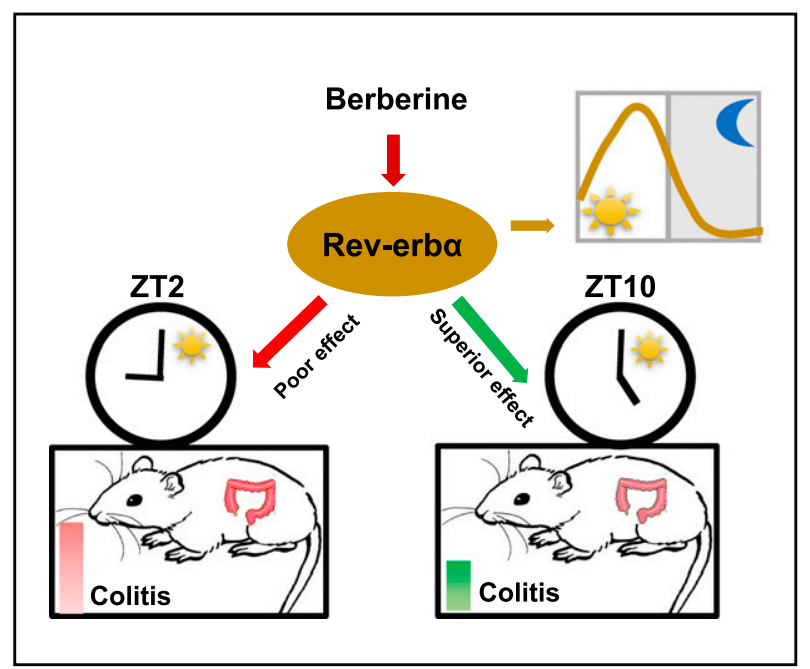

B

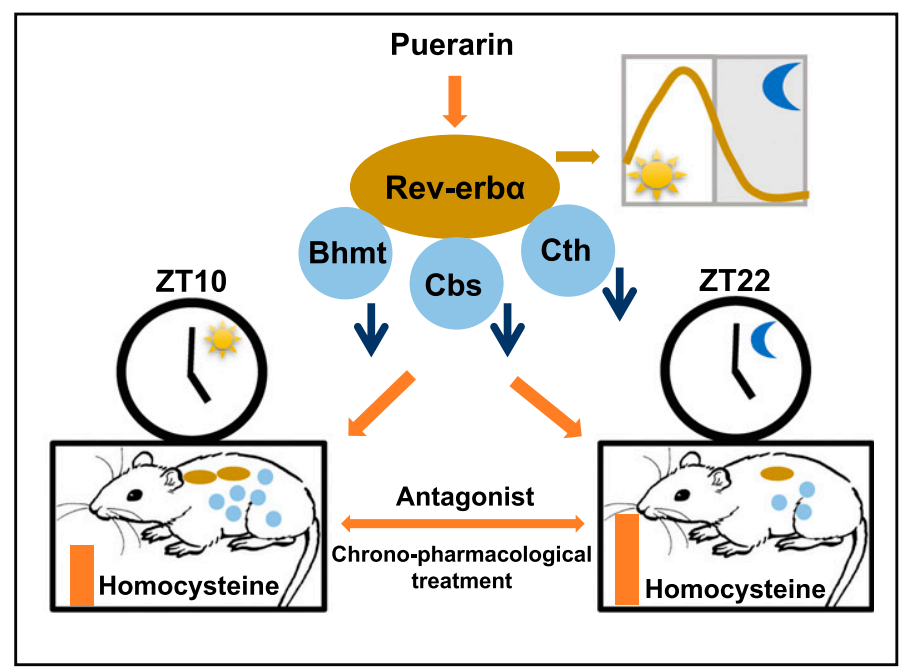

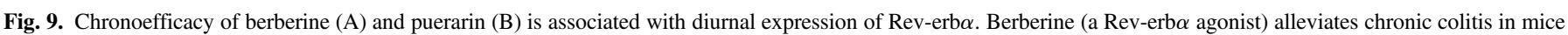

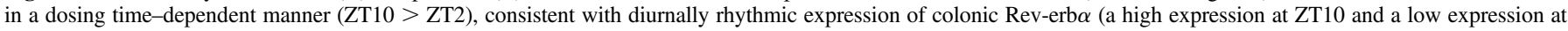

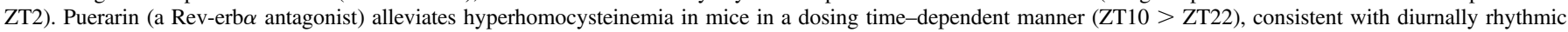
expression of hepatic Rev-erb $\alpha$ (a high expression at ZT10 and a low expression at ZT22).

reductase is expressed at higher levels at night (Jones and Schoeller, 1990).

\section{Concluding Remarks}

Many drug-metabolizing enzymes in mice have been identified to be rhythmically expressed in the liver and intestine. By contrast, a very limited number of human P450 genes (i.e., CYP2D6 and CYP3A4) are characterized as circadian genes in vitro. Extensive studies with cells and mice in recent years have revealed two modes (i.e., a general mode and an alternative mode) for generation of diurnal rhythmicity in drugmetabolizing enzymes. In the general mode, circadian clock genes generate and regulate diurnal gene expression via transcriptional actions on one or two of three cis-elements (i.e., E-box, D-box, and RevRE or RORE). The alternative mode involves cycling NRs, such as $\mathrm{Hnf} 4 \alpha$ and Ppar- $\gamma$. The rhythms of cycling NRs can be propagated to the downstream target genes, many of which are drug-processing genes.

The rest-activity cycle is inverted between humans (diurnal creatures) and rodents (nocturnal species). This may raise serious concerns about whether the circadian mechanisms for drug metabolism could be translated from rodents to humans. However, the basic mechanisms for circadian clock and for circadian gene expression are thought to be well conserved in mammals. Although the diurnal patterns of mouse drug-processing genes cannot be directly mapped to those of human counterparts, the regulatory relationships of circadian oscillators with their targets should be preserved between humans and mice. Future studies are suggested to validate the discovered circadian mechanisms in mice for drug-processing genes using human-derived cells and primates. These studies are useful in attempting to predict circadian patterns of drug-processing genes in humans.

Theoretically, circadian metabolism would result in chronoefficacy in addition to chronotoxicity due to diurnal variations in drug exposure caused by circadian metabolism. Contrasting with well established relationships of circadian metabolism and pharmacokinetics with chronotoxicity, the experimental evidence is still lacking in metabolism-based chronoefficacy. This is probably because very few or no studies were ever performed to examine both circadian metabolism and chronoefficacy. Such studies appear to be essential to advance drug chronotherapeutics because the best timing for drug administration should be derived by taking both drug toxicity and efficacy into consideration.

\section{Authorship Contributions}

Wrote or contributed to the writing of the manuscript: $\mathrm{Lu}$, Zhao, $\mathrm{Chen}, \mathrm{Wu}$.

\section{References}

Akamine T, Koyanagi S, Kusunose N, Hashimoto $\mathrm{H}$, Taniguchi M, Matsunaga N, and Ohdo $\mathrm{S}(2015)$ Dosing time-dependent changes in the analgesic effect of pregabalin on diabetic neuropathy in mice. J Pharmacol Exp Ther 354:65-72.

Almazroo OA, Miah MK, and Venkataramanan R(2017) Drug metabolism in the liver. Clin Liver Dis 21:1-20.

Ando H, Yanagihara H, Sugimoto K, Hayashi Y, Tsuruoka S, Takamura T, Kaneko S, and Fujimura A(2005) Daily rhythms of P-glycoprotein expression in mice. Chronobiol Int 22: $655-665$.

Awad K and Banach M(2018) The optimal time of day for statin administration: a review of current evidence. Curr Opin Lipidol 29:340-345.

Baraldo M(2008) The influence of circadian rhythms on the kinetics of drugs in humans. Expert Opin Drug Metab Toxicol 4:175-192.

Bass J and Lazar MA(2016) Circadian time signatures of fitness and disease. Science 354:994-999.

Bass J and Takahashi JS(2010) Circadian integration of metabolism and energetics. Science 330: 1349-1354.

Belandia B and Parker MG(2003) Nuclear receptors: a rendezvous for chromatin remodeling factors. Cell 114:277-280.

Benedetti MS, Whomsley R, Poggesi I, Cawello W, Mathy FX, Delporte ML, Papeleu P, and Watelet JB(2009) Drug metabolism and pharmacokinetics. Drug Metab Rev 41:344-390.

Benet LZ(2009) The drug transporter-metabolism alliance: uncovering and defining the interplay. Mol Pharm 6:1631-1643.

Bruguerolle B(1998) Chronopharmacokinetics. Current status. Clin Pharmacokinet 35:83-94.

Castanon-Cervantes O, Wu M, Ehlen JC, Paul K, Gamble KL, Johnson RL, Besing RC, Menaker M, Gewirtz AT, and Davidson AJ(2010) Dysregulation of inflammatory responses by chronic circadian disruption. J Immunol 185:5796-5805.

Cerny MA(2016) Prevalence of non-cytochrome P450-mediated metabolism in Food and Drug Administration-approved oral and intravenous drugs: 2006-2015. Drug Metab Dispos 44: $1246-1252$.

Chen M, Guan B, Xu H, Yu F, Zhang T, and Wu B(2019a) The molecular mechanism regulating diurnal rhythm of flavin-containing monooxygenase 5 in mouse liver. Drug Metab Dispos 47: $1333-1342$.

Chen M, Guo L, Dong D, Yu F, Zhang T, and Wu B(2019b) The nuclear receptor Shp regulates morphine withdrawal syndrome via modulation of Ugt $2 \mathrm{~b}$ expression in mice. Biochem Pharmacol 161:163-172.

Chen M, Zhou C, Xu H, Zhang T, and Wu B(2020) Chronopharmacological targeting of Rev-erb $\alpha$ by puerarin alleviates hyperhomocysteinemia in mice. Biomed Pharmacother 125:109936.

Chen Y, Coulter S, Jetten AM, and Goldstein JA(2009) Identification of human CYP2C8 as a retinoid-related orphan nuclear receptor target gene. J Pharmacol Exp Ther 329:192-201.

Chen Y, Tang Y, Guo C, Wang J, Boral D, and Nie D(2012) Nuclear receptors in the multidrug resistance through the regulation of drug-metabolizing enzymes and drug transporters. Biochem Pharmacol 83:1112-1126.

Choi $\mathrm{YH}$ and $\mathrm{Yu} \mathrm{AM}(2014) \mathrm{ABC}$ transporters in multidrug resistance and pharmacokinetics, and strategies for drug development. Curr Pharm Des 20:793-807. 
Christians U, Schmitz V, and Haschke M(2005) Functional interactions between P-glycoprotein and CYP3A in drug metabolism. Expert Opin Drug Metab Toxicol 1:641-654.

Curtis AM, Bellet MM, Sassone-Corsi P, and O'Neill LA(2014) Circadian clock proteins and immunity. Immunity 40:178-186.

Dallmann R, Brown SA, and Gachon F(2014) Chronopharmacology: new insights and therapeutic implications. Annu Rev Pharmacol Toxicol 54:339-361.

Deng J, Guo L, and Wu B(2018) Circadian regulation of hepatic cytochrome P450 2a5 by peroxisome proliferator-activated receptor $\gamma$. Drug Metab Dispos 46:1538-1545.

Döring B and Petzinger E(2014) Phase 0 and phase III transport in various organs: combined concept of phases in xenobiotic transport and metabolism. Drug Metab Rev 46:261-282.

Duez H, van der Veen JN, Duhem C, Pourcet B, Touvier T, Fontaine C, Derudas B, Baugé E, Havinga R, Bloks VW, et al.(2008) Regulation of bile acid synthesis by the nuclear receptor Rev-erbalpha. Gastroenterology 135:689-698.

Evans RM and Mangelsdorf DJ(2014) Nuclear receptors, RXR, and the big bang. Cell 157: 255-266.

Feng D and Lazar MA(2012) Clocks, metabolism, and the epigenome. Mol Cell 47:158-167.

Filipski E, Berland E, Ozturk N, Guettier C, van der Horst GT, Lévi F, and Okyar A(2014) Optimization of irinotecan chronotherapy with P-glycoprotein inhibition. Toxicol Appl Pharmacol 274:471-479.

Fujiwara Y, Ando H, Ushijima K, Horiguchi M, Yamashita C, and Fujimura A(2017) Dosingtime-dependent effect of rivaroxaban on coagulation activity in rats. J Pharmacol Sci 134: 234-238

Gachon F, Olela FF, Schaad O, Descombes P, and Schibler U(2006) The circadian PAR-domain basic leucine zipper transcription factors DBP, TEF, and HLF modulate basal and inducible xenobiotic detoxification. Cell Metab 4:25-36.

Gale JE, Cox HI, Qian J, Block GD, Colwell CS, and Matveyenko AV(2011) Disruption of circadian rhythms accelerates development of diabetes through pancreatic beta-cell loss and dysfunction. J Biol Rhythms 26:423-433.

Gaspar LS, Álvaro AR, Carmo-Silva S, Mendes AF, Relógio A, and Cavadas C(2019) The importance of determining circadian parameters in pharmacological studies. Br J Pharmacol 176:2827-2847.

Germain A and Kupfer DJ(2008) Circadian rhythm disturbances in depression. Hum Psychopharmacol 23:571-585.

Gery S and Koeffler HP(2010) Circadian rhythms and cancer. Cell Cycle 9:1097-1103.

Gorbacheva VY, Kondratov RV, Zhang R, Cherukuri S, Gudkov AV, Takahashi JS, and Antoch MP(2005) Circadian sensitivity to the chemotherapeutic agent cyclophosphamide depends on the functional status of the CLOCK/BMAL1 transactivation complex. Proc Natl Acad Sci USA 102 $3407-3412$.

Guengerich FP(2006) Cytochrome P450s and other enzymes in drug metabolism and toxicity. AAPS J 8:E101-E111

Hadadi E, Taylor W, Li X, Aslan Y, Villote M, Rivière J, Duvallet G, Auriau C, Dulong S, Letron IR, et al.(2019) Chronic circadian disruption modulates breast cancer cell stemness and their immune microenvironment to drive metastasis in mice. bioRxiv.

Hamdan AM, Koyanagi S, Wada E, Kusunose N, Murakami Y, Matsunaga N, and Ohdo S(2012) Intestinal expression of mouse $\mathrm{Abcg} 2 / \mathrm{breast}$ cancer resistance protein (BCRP) gene is under control of circadian clock-activating transcription factor-4 pathway. J Biol Chem 287: 17224-17231.

Harding HP and Lazar MA(1993) The orphan receptor Rev-ErbA alpha activates transcription via a novel response element. Mol Cell Biol 13:3113-3121.

Harding HP and Lazar MA(1995) The monomer-binding orphan receptor Rev-Erb represses transcription as a dimer on a novel direct repeat [published correction appears in Mol Cell Biol (1995) 15:6479]. Mol Cell Biol 15:4791-4802.

Hatanaka F, Matsubara C, Myung J, Yoritaka T, Kamimura N, Tsutsumi S, Kanai A, Suzuki Y, Sassone-Corsi P, Aburatani H, et al.(2010) Genome-wide profiling of the core clock protein BMAL1 targets reveals a strict relationship with metabolism. Mol Cell Biol 30:5636-5648.

Horiguchi M, Koyanagi S, Hamdan AM, Kakimoto K, Matsunaga N, Yamashita C, and Ohdo S(2013) Rhythmic control of the ARF-MDM2 pathway by ATF4 underlies circadian accumulation of p53 in malignant cells. Cancer Res 73:2639-2649.

Huang P, Ceccatelli S, and Rannug A(2002) A study on diurnal mRNA expression of CYP1A1, AHR, ARNT, and PER2 in rat pituitary and liver. Environ Toxicol Pharmacol 11:119-126.

Innominato PF, Lévi FA, and Bjarnason GA(2010) Chronotherapy and the molecular clock: clinical implications in oncology. Adv Drug Deliv Rev 62:979-1001.

Iurisci I, Filipski E, Sallam H, Harper F, Guettier C, Maire I, Hassan M, Iacobelli S, and Lévi F(2009) Liver circadian clock, a pharmacologic target of cyclin-dependent kinase inhibitor seliciclib. Chronobiol Int 26:1169-1188.

Jeong EJ, Liu X, Jia X, Chen J, and Hu M(2005) Coupling of conjugating enzymes and efflux transporters: impact on bioavailability and drug interactions. Curr Drug Metab 6:455-468

Jones PJ and Schoeller DA(1990) Evidence for diurnal periodicity in human cholesterol synthesis J Lipid Res 31:667-673.

Karatsoreos IN(2014) Links between circadian rhythms and psychiatric disease. Front Behav Neurosci 8:162.

Kaur G, Phillips C, Wong K, and Saini B(2013) Timing is important in medication administration: a timely review of chronotherapy research. Int J Clin Pharm 35:344-358.

Kawase A, Ohgami T, Yoshida I, Tsunokuni Y, and Iwaki M(2013) Diurnal variation of nuclear receptors in mice with or without fasting. Pharmacol Pharm 4:240.

Kervezee L, Hartman R, van den Berg DJ, Shimizu S, Emoto-Yamamoto Y, Meijer JH, and de Lange EC(2014) Diurnal variation in P-glycoprotein-mediated transport and cerebrospinal fluid turnover in the brain. AAPS $J$ 16:1029-1037.

Kettner NM, Mayo SA, Hua J, Lee C, Moore DD, and Fu L(2015) Circadian dysfunction induces leptin resistance in mice. Cell Metab 22:448-459.

Kotaka M, Onishi Y, Ohno T, Akaike T, and Ishida N(2008) Identification of negative transcriptional factor E4BP4-binding site in the mouse circadian-regulated gene Mdr2. Neurosci Res 60:307-313.

Koyanagi S, Kuramoto Y, Nakagawa H, Aramaki H, Ohdo S, Soeda S, and Shimeno H(2003) A molecular mechanism regulating circadian expression of vascular endothelial growth factor in tumor cells. Cancer Res 63:7277-7283.

Kusunose N, Koyanagi S, Hamamura K, Matsunaga N, Yoshida M, Uchida T, Tsuda M, Inoue K, and Ohdo S(2010) Molecular basis for the dosing time-dependency of anti-allodynic effects of gabapentin in a mouse model of neuropathic pain. Mol Pain 6:83.
Lauriola M, Enuka Y, Zeisel A, D'Uva G, Roth L, Sharon-Sevilla M, Lindzen M, Sharma K, Nevo N, Feldman M, et al.(2014) Diurnal suppression of EGFR signalling by glucocorticoids and implications for tumour progression and treatment. Nat Commun 5:5073.

Lavery DJ, Lopez-Molina L, Margueron R, Fleury-Olela F, Conquet F, Schibler U, and Bonfils C(1999) Circadian expression of the steroid 15 alpha-hydroxylase (Cyp2a4) and coumarin 7 hydroxylase (Cyp2a5) genes in mouse liver is regulated by the PAR leucine zipper transcription factor DBP. Mol Cell Biol 19:6488-6499.

Lévi F(2003) Circadian Rhythms in 5-fluorouracil Pharmacology and Therapeutic Applications. Fluoropyrimidines in Cancer Therapy pp 107-128, Humana Press, Totowa, NJ.

Lévi F and Okyar A(2011) Circadian clocks and drug delivery systems: impact and opportunities in chronotherapeutics. Expert Opin Drug Deliv 8:1535-1541.

Levi F and Schibler U(2007) Circadian rhythms: mechanisms and therapeutic implications. Anпи Rev Pharmacol Toxicol 47:593-628.

Li Y, Meng Q, Yang M, Liu D, Hou X, Tang L, Wang X, Lyu Y, Chen X, Liu K, et al.(2019) Current trends in drug metabolism and pharmacokinetics. Acta Pharm Sin B 9:1113-1144.

Lin P, An F, Xu X, Zhao L, Liu L, Liu N, Wang P, Liu J, Wang L, and Li M(2015) Chronopharmacodynamics and mechanisms of antitumor effect induced by erlotinib in xenograftbearing nude mice. Biochem Biophys Res Commun 460:362-367.

Lin Y, Wang S, Zhou Z, Guo L, Yu F, and Wu B(2019a) Bmal1 regulates circadian expression of cytochrome P450 3a11 and drug metabolism in mice. Commun Biol 2:378.

Lin Y, Zhou Z, Yang Z, Gao L, Wang S, Yu P, and Wu B(2019b) Circadian Cyp3a11 metabolism contributes to chronotoxicity of hypaconitine in mice. Chem Biol Interact 308:288-293.

Liu AC, Tran HG, Zhang EE, Priest AA, Welsh DK, and Kay SA(2008) Redundant function of REV-ERBalpha and beta and non-essential role for Bmall cycling in transcriptional regulation of intracellular circadian rhythms. PLoS Genet 4:e1000023.

Mangelsdorf DJ, Thummel C, Beato M, Herrlich P, Schütz G, Umesono K, Blumberg B, Kastner P, Mark M, Chambon P, et al.(1995) The nuclear receptor superfamily: the second decade. Cell 83:835-839.

Matsunaga N, Ogino T, Hara Y, Tanaka T, Koyanagi S, and Ohdo S(2018) Optimized dosing schedule based on circadian dynamics of mouse breast cancer stem cells improves the antitumor effects of aldehyde dehydrogenase inhibitor. Cancer Res 78:3698-3708.

Mattis J and Sehgal A(2016) Circadian rhythms, sleep, and disorders of aging. Trends Endocrinol Metab 27:192-203.

Maury E, Ramsey KM, and Bass J(2010) Circadian rhythms and metabolic syndrome: from experimental genetics to human disease. Circ Res 106:447-462.

Meech R, Hu DG, McKinnon RA, Mubarokah SN, Haines AZ, Nair PC, Rowland A, and Mackenzie PI(2019) The UDP-Glycosyltransferase (UGT) superfamily: new members, new functions, and novel paradigms. Physiol Rev 99:1153-1222.

Minami Y, Ode KL, and Ueda HR(2013) Mammalian circadian clock: the roles of transcriptional repression and delay. Handb Exp Pharmacol 217:359-377.

Mitsui S, Yamaguchi S, Matsuo T, Ishida Y, and Okamura H(2001) Antagonistic role of E4BP4 and PAR proteins in the circadian oscillatory mechanism. Genes Dev 15:995-1006.

Mrosovsky N(1996) Locomotor activity and non-photic influences on circadian clocks. Biol Rev Camb Philos Soc 71:343-372.

Mudra DR, Desino KE, and Desai PV(2011) In silico, in vitro and in situ models to assess interplay between CYP3A and P-gp. Curr Drug Metab 12:750-773.

Nakabayashi H, Ohta Y, Yamamoto M, Susuki Y, Taguchi A, Tanabe K, Kondo M, Hatanaka M, Nagao Y, and Tanizawa Y(2013) Clock-controlled output gene Dbp is a regulator of Arnt/Hif- $1 \beta$ gene expression in pancreatic islet $\beta$-cells. Biochem Biophys Res Commun 434: 370-375.

Nakagawa H, Takiguchi T, Nakamura M, Furuyama A, Koyanagi S, Aramaki H, Higuchi S, and Ohdo S(2006) Basis for dosing time-dependent change in the anti-tumor effect of imatinib in mice. Biochem Pharmacol 72:1237-1245.

Nakamura K, Hirayama-Kurogi M, Ito S, Kuno T, Yoneyama T, Obuchi W, Terasaki T, and Ohtsuki S(2016) Large-scale multiplex absolute protein quantification of drug-metabolizing enzymes and transporters in human intestine, liver, and kidney microsomes by SWATH-MS: comparison with MRM/SRM and HR-MRM/PRM. Proteomics 16:2106-2117.

Narumi R, Shimizu Y, Ukai-Tadenuma M, Ode KL, Kanda GN, Shinohara Y, Sato A, Matsumoto $\mathrm{K}$, and Ueda HR(2016) Mass spectrometry-based absolute quantification reveals rhythmic variation of mouse circadian clock proteins. Proc Natl Acad Sci USA 113:E3461-E3467.

Noshiro M, Usui E, Kawamoto T, Kubo H, Fujimoto K, Furukawa M, Honma S, Makishima M, Honma K, and Kato Y(2007) Multiple mechanisms regulate circadian expression of the gene for cholesterol 7alpha-hydroxylase (Cyp7a), a key enzyme in hepatic bile acid biosynthesis. J Biol Rhythms 22:299-311.

Oh JH, Lee JH, Han DH, Cho S, and Lee YJ(2017) Circadian clock is involved in regulation of hepatobiliary transport mediated by multidrug resistance-associated protein 2. J Pharm Sci 106: 2491-2498.

Ohdo S, Koyanagi S, and Matsunaga N(2019) Chronopharmacological strategies focused on chrono-drug discovery. Pharmacol Ther 202:72-90.

Ohtsuki S, Schaefer O, Kawakami H, Inoue T, Liehner S, Saito A, Ishiguro N, Kishimoto W, Ludwig-Schwellinger E, Ebner T, et al.(2012) Simultaneous absolute protein quantification of transporters, cytochromes P450, and UDP-glucuronosyltransferases as a novel approach for the characterization of individual human liver: comparison with mRNA levels and activities. Drug Metab Dispos 40:83-92.

Oiwa A, Kakizawa T, Miyamoto T, Yamashita K, Jiang W, Takeda T, Suzuki S, and Hashizume $\mathrm{K}$ (2007) Synergistic regulation of the mouse orphan nuclear receptor SHP gene promoter by CLOCK-BMAL1 and LRH-1. Biochem Biophys Res Commun 353:895-901.

Okazaki F, Matsunaga N, Hamamura K, Suzuki K, Nakao T, Okazaki H, Kutsukake M, Fukumori S, Tsuji Y, and To H(2017) Administering xCT inhibitors based on circadian clock improves antitumor effects. Cancer Res 77:6603-6613.

Okyar A, Piccolo E, Ahowesso C, Filipski E, Hossard V, Guettier C, La Sorda R, Tinari N, Iacobelli S, and Lévi F(2011) Strain- and sex-dependent circadian changes in abcc2 transporter expression: implications for irinotecan chronotolerance in mouse ileum. PLoS One 6:e20393.

Ou Z, Shi X, Gilroy RK, Kirisci L, Romkes M, Lynch C, Wang H, Xu M, Jiang M, Ren S, et al.(2013) Regulation of the human hydroxysteroid sulfotransferase (SULT2A1) by ROR $\alpha$ and ROR $\gamma$ and its potential relevance to human liver diseases. Mol Endocrinol 27:106-115.

Pan X, Zhang Y, Wang L, and Hussain MM(2010) Diurnal regulation of MTP and plasma triglyceride by CLOCK is mediated by SHP. Cell Metab 12:174-186.

Paschos GK, Baggs JE, Hogenesch JB, and FitzGerald GA (2010) The role of clock genes in pharmacology. Annu Rev Pharmacol Toxicol 50:187-214. 
Portaluppi F, Tiseo R, Smolensky MH, Hermida RC, Ayala DE, and Fabbian F(2012) Circadian rhythms and cardiovascular health. Sleep Med Rev 16:151-166.

Preitner N, Damiola F, Lopez-Molina L, Zakany J, Duboule D, Albrecht U, and Schibler U(2002) The orphan nuclear receptor REV-ERBalpha controls circadian transcription within the positive limb of the mammalian circadian oscillator. Cell 110:251-260.

Radzialowski FM and Bousquet WF(1968) Daily rhythmic variation in hepatic drug metabolism in the rat and mouse. J Pharmacol Exp Ther 163:229-238.

Ripperger JA and Schibler U(2006) Rhythmic CLOCK-BMAL1 binding to multiple E-box motifs drives circadian Dbp transcription and chromatin transitions. Nat Genet 38:369-374.

Ruben MD, Smith DF, FitzGerald GA, and Hogenesch JB(2019) Dosing time matters. Science 365 547-549.

Schaefer O, Ohtsuki S, Kawakami H, Inoue T, Liehner S, Saito A, Sakamoto A, Ishiguro N, Matsumaru T, Terasaki T, et al.(2012) Absolute quantification and differential expression of drug transporters, cytochrome P450 enzymes, and UDP-glucuronosyltransferases in cultured primary human hepatocytes. Drug Metab Dispos 40:93-103.

Schinkel AH and Jonker JW(2003) Mammalian drug efflux transporters of the ATP binding cassette (ABC) family: an overview. Adv Drug Deliv Rev 55:3-29.

Shetty A, Hsu JW, Manka PP, and Syn WK(2018) Role of the circadian clock in the metabolic syndrome and nonalcoholic fatty liver disease. Dig Dis Sci 63:3187-3206.

Takahashi JS(2017) Transcriptional architecture of the mammalian circadian clock. Nat Rev Genet 18: $164-179$

Takiguchi T, Tomita M, Matsunaga N, Nakagawa H, Koyanagi S, and Ohdo S(2007) Molecular basis for rhythmic expression of CYP3A4 in serum-shocked HepG2 cells. Pharmacogene Genomics 17:1047-1056.

Tanimura N, Kusunose N, Matsunaga N, Koyanagi S, and Ohdo S(2011) Aryl hydrocarbon receptor-mediated Cyplal expression is modulated in a CLOCK-dependent circadian manner. Toxicology 290:203-207.

Testa B, Pedretti A, and Vistoli G(2012) Reactions and enzymes in the metabolism of drugs and other xenobiotics. Drug Discov Today 17:549-560.

Thaiss CA, Zeevi D, Levy M, Segal E, and Elinav E (2015) A day in the life of the meta-organism: diurnal rhythms of the intestinal microbiome and its host. Gut Microbes 6:137-142.

Tolson AH and Wang H(2010) Regulation of drug-metabolizing enzymes by xenobiotic receptors: PXR and CAR. Adv Drug Deliv Rev 62:1238-1249.

Tong Y, Zeng P, Zhang T, Zhao M, Yu P, and Wu B(2019) The transcription factor E4bp4 regulates the expression and activity of Cyp3a11 in mice. Biochem Pharmacol 163: 215-224.

Wada T, Kang HS, Angers M, Gong H, Bhatia S, Khadem S, Ren S, Ellis E, Strom SC, Jetten AM et al.(2008) Identification of oxysterol 7alpha-hydroxylase (Cyp7b1) as a novel retinoid-related orphan receptor alpha (RORalpha) (NR1F1) target gene and a functional cross-talk between RORalpha and liver X receptor (NR1H3). Mol Pharmacol 73:891-899.

Wang S, Lin Y, Yuan X, Li F, Guo L, and Wu B(2018) REV-ERB $\alpha$ integrates colon clock with experimental colitis through regulation of NF-кB/NLRP3 axis. Nat Commun 9:4246.

Wang S, Lin Y, Zhou Z, Gao L, Yang Z, Li F, and Wu B(2019) Circadian clock gene Bmall regulates bilirubin detoxification: a potential mechanism of feedback control of hyperbilirubinemia. Theranostics 9:5122-5133

Wang S, Xing H, Zhao M, Lu D, Li Z, Dong D, and Wu B(2016) Recent advances in understanding of kinetic interplay between phase II metabolism and efflux transport. Curr Drug Metab 17:922-929.

Wilkinson GR(2005) Drug metabolism and variability among patients in drug response. $N$ Engl J Med 352:2211-2221.

Winter C, Silvestre-Roig C, Ortega-Gomez A, Lemnitzer P, Poelman H, Schumski A, Winter J, Drechsler M, de Jong R, Immler R, et al.(2018) Chrono-pharmacological targeting of the CCL2 CCR2 axis ameliorates atherosclerosis. Cell Metab 28:175-182.e5.
Wu B(2012) Pharmacokinetic interplay of phase II metabolism and transport: a theoretical study. J Pharm Sci 101:381-393.

$\mathrm{Xu} \mathrm{C}, \mathrm{Li} \mathrm{CY}$, and Kong AN(2005) Induction of phase I, II and III drug metabolism/transport by xenobiotics. Arch Pharm Res 28:249-268.

Yang X, Downes M, Yu RT, Bookout AL, He W, Straume M, Mangelsdorf DJ, and Evans RM(2006) Nuclear receptor expression links the circadian clock to metabolism. Cell 126: 801-810.

Yang Z, Lin Y, Gao L, Zhou Z, Wang S, Dong D, and Wu B(2020) Circadian clock regulates metabolism and toxicity of Fuzi (lateral root of Aconitum carmichaeli Debx) in mice. Phytomedicine 67:153161.

Yin L and Lazar MA(2005) The orphan nuclear receptor Rev-erbalpha recruits the N-CoR/histone deacetylase 3 corepressor to regulate the circadian Bmall gene. Mol Endocrinol 19:1452-1459.

Yoo SH, Yamazaki S, Lowrey PL, Shimomura K, Ko CH, Buhr ED, Siepka SM, Hong HK, Oh WJ, Yoo OJ, et al.(2004) PERIOD2:LUCIFERASE real-time reporting of circadian dynamics reveals persistent circadian oscillations in mouse peripheral tissues. Proc Natl Acad Sci USA 101: 5339-5346.

Yu F, Zhang T, Zhou C, Xu H, Guo L, Chen M, and Wu B(2019) The circadian clock gene Bmall controls intestinal exporter MRP2 and drug disposition. Theranostics 9:2754-2767.

Zamir I, Harding HP, Atkins GB, Hörlein A, Glass CK, Rosenfeld MG, and Lazar MA(1996) A nuclear hormone receptor corepressor mediates transcriptional silencing by receptors with distinct repression domains. Mol Cell Biol 16:5458-5465.

Zanger UM and Schwab M(2013) Cytochrome P450 enzymes in drug metabolism: regulation of gene expression, enzyme activities, and impact of genetic variation. Pharmacol Ther 138: $103-141$.

Zhang T, Chen M, Guo L, Yu F, Zhou C, Xu H, and Wu B(2019a) Reverse erythroblastosis virus $\alpha$ antagonism promotes homocysteine catabolism and ammonia clearance. Hepatology 70: $1770-1784$.

Zhang T, Guo L, Yu F, Chen M, and Wu B(2019b) The nuclear receptor Rev-erb $\alpha$ participates in circadian regulation of Ugt2b enzymes in mice. Biochem Pharmacol 161:89-97.

Zhang T, Yu F, Guo L, Chen M, Yuan X, and Wu B(2018) Small heterodimer partner regulates circadian cytochromes $\mathrm{p} 450$ and drug-induced hepatotoxicity. Theranostics 8:5246-5258.

Zhang YK, Yeager RL, and Klaassen CD(2009) Circadian expression profiles of drug-processing genes and transcription factors in mouse liver. Drug Metab Dispos 37:106-115.

Zhao M, Xing H, Chen M, Dong D, and Wu B(2019a) Circadian clock-controlled drug metabolism and transport. Xenobiotica $1-11$.

Zhao M, Zhang T, Yu F, Guo L, and Wu B(2018) E4bp4 regulates carboxylesterase 2 enzymes through repression of the nuclear receptor Rev-erb $\alpha$ in mice. Biochem Pharmacol 152:293-301.

Zhao M, Zhao H, Deng J, Guo L, and Wu B (2019b) Role of the CLOCK protein in liver detoxification. Br J Pharmacol 176:4639-4652.

Zhou C, Yu F, Zeng P, Zhang T, Huang H, Chen W, and Wu B(2019a) Circadian sensitivity to the cardiac glycoside oleandrin is associated with diurnal intestinal P-glycoprotein expression. Biochem Pharmacol 169:113622.

Zhou Z, Lin Y, Gao L, Yang Z, Wang S, and Wu B(2019b) Cyp3a11 metabolism-based chronotoxicity of brucine in mice. Toxicol Lett 313:188-195.

Zhou Z, Lin Y, Gao L, Yang Z, Wang S, and Wu B(2020) Circadian pharmacological effects of berberine on chronic colitis in mice: role of the clock component Rev-erb $\alpha$. Biochem Pharmacol 172:113773.

Address correspondence to: Dr. Baojian Wu, College of Pharmacy, Jinan University, Guangzhou 510632, China. E-mail: bj.wu@hotmail.com 